6 Clermont-Ferrand, France

7 2MET, Unité Matériaux Et Transformations, Bâtiment C6, University of Lille, 59655

8 Villeneuve d'Ascq, Lille, France.

9 molten geological materials: Effect of evolving melt texture

\author{
D. Freitas ${ }^{1 *}$, G. Manthilake ${ }^{1}$, J. Chantel $^{2, \dagger}$, M. A. Bouhifd ${ }^{1}$, D. Andrault ${ }^{1}$
}

*Corresponding author: (damien.freitas@uca.fr +334.73.34.67.23, ORCID: 0000-0002-17224081)

\section{Key Points:}

1. Electrical conductivity increases with evolving melt texture; transient melt textures can underestimate the electrical conductivity.

2. Acoustic velocities are not strongly affected by evolving melt texture for highly wetting melt

3. Acoustic velocities measurements are more appropriate for estimating the melt fraction. 


\section{Abstract}

Comparison between geophysical observations and laboratory measurements yields contradicting estimations of the melt fraction for the partially molten regions of the Earth, highlighting potential disagreements between laboratory-based electrical conductivity and seismic wave velocity measurement techniques. In this study, we performed simultaneous acoustic wave velocity and electrical conductivity measurements on a simplified partial melt analogue (olivine + mid oceanic ridge basalt, MORB) at $2.5 \mathrm{GPa}$ and up to $1650 \mathrm{~K}$. We aim to investigate the effect of ongoing textural modification of partially molten peridotite analog on both electrical conductivity and sound wave velocity. Acoustic wave velocity (Vp and Vs) and EC are measured on an identical sample presenting the same melt texture, temperature gradient, stress field and chemical impurities. We observe a sharp decrease of acoustic wave velocities and increase of electrical conductivity in response to melting of MORB component. At constant temperature of $1650 \mathrm{~K}$, electrical conductivity gradually increases, whereas acoustic velocities remain relatively constant. While the total MORB components melt instantaneously above the melting temperature, the melt interconnectivity and the melt distribution should evolve with time, affecting the electrical conduction. Consequently, our experimental observations suggest that acoustic velocities respond spontaneously to the melt volume fraction for melt with high wetting properties, whereas electrical conduction is significantly affected by subsequent melt texture modifications. We find that acoustic velocity measurements are thus better suited to the determination of the melt fraction of a partially molten sample at the laboratory time scale ( hours). Based on our estimations, the reduced Vs velocity in the major part of the low velocity zone (LVZ) away from spreading ridges can be explained by 0.3 to 0.8 vol. \% volatile-bearing 
41 melt and the high $\mathrm{Vp} / \mathrm{Vs}$ ratio obtained for these melt fractions (1.82-1.87) are compatible with 42 geophysical observations.

43 Keywords: Electrical Conductivity, Acoustic Wave Velocity, Low Velocity Zone, Dihedral 44 angle, Melt fraction, MORB.

45 


\section{Introduction}

The Earth's asthenosphere is characterized by a region of high electrical conductivity (> $0.05 \mathrm{~S} / \mathrm{m}$ ) [Shankland and Waff, 1977], 3-8 \% reduction of acoustic wave velocity and high seismic attenuation [Anderson and Sammis, 1970; Romanowicz, 1995]. A low degree of partial melting has often been considered as a viable explanation (partial melting hypothesis), because the magnitude of seismic and electrical anomalies cannot be explained by the temperature effect alone [Fischer et al., 2010]. Alternative mechanisms based on solid state processes, such as anelastic relaxation [Goetze, 1977; Stixrude and Lithgow-Bertelloni, 2005] and hydrogen diffusion [Karato, 1990] in mantle minerals have also been proposed (null hypothesis). However, the recent finding of young alkali basalt $(<10 \mathrm{Ma})$ on the 135 million-year-old Pacific Plate [Hirano et al., 2006] provides strong physical evidence for partial melting at the top of the asthenosphere.

The criteria for melting in the asthenosphere have been discussed in a number of recent papers [Galer and O’Nions, 1986; Plank and Langmuir, 1992; Dasgupta and Hirschmann, 2006]. Volatile-assisted melting in the asthenosphere is favored as the mantle temperatures at the relevant depths are expected to be lower than the dry peridotite solidus [Dasgupta and Hirschmann, 2006]. The volatile contents of the primitive mantle samples suggest mantle abundances of $\sim 150$ wt. ppm of $\mathrm{H}_{2} \mathrm{O}$ and $\sim 100$ wt. ppm of $\mathrm{CO}_{2}$ [Saal et al., 2002], while $\mathrm{CO}_{2}$ contents of up to 1800 wt. ppm have been reported in undegased sources [Cartigny et al., 2008]. The recent discovery of young alkali basalt associated with volcanism along fractures in the lithosphere indicates up to 5 wt. \% $\mathrm{CO}_{2}$ and 1.0 wt. \% of $\mathrm{H}_{2} \mathrm{O}$ volatile contents [Okumura and Hirano, 2013]. However, the measurements based on melt inclusions in minerals and quenched glasses indicate a global average of about 3000 wt. ppm of $\mathrm{H}_{2} \mathrm{O}$ and 170 wt. ppm of $\mathrm{CO}_{2}$ in 
natural MORB [Naumov et al., 2014]. A substantial contribution of volatiles to the melting can be expected at low temperature regions in the asthenosphere [Sifré et al., 2014; Yoshino et al., 2010].

The reduced seismic velocity and elevated electrical conductivity have been widely used as evidence for the presence of melt in the Earth's interior [Anderson and Sammis, 1970]. The magnitudes of the seismic velocity and conductivity variations are directly linked to the melt fraction, therefore comparison of geophysical data with laboratory models has long been considered as the most plausible way to quantify the melt contents in partially molten regions of the Earth [Anderson and Sammis, 1970; Shankland and Waff, 1977]. The accurate determination of melt volume fraction in the asthenosphere is a key constraint for the plate tectonics and mantle convection models [Schmerr, 2012]. Apart from identifying the partially molten regions and quantifying the melt fractions, the seismic and electrical methods can also be used to characterize their spatial distribution. For example, laboratory-based experiments [Caricchi et al., 2011; Zhang et al., 2014; Pommier et al., 2015] have been able to attribute the seismic and electrical anisotropies observed at spreading ridge environments to the shear localization of melt due to plate motion.

The presence of a melt significantly modifies the viscoelastic properties of mineral assemblages. The critical parameters are the volume fraction and the melt microstructures [Kohlstedt, 1992]. Unfortunately, experimental determinations of seismic velocity on realistic melt compositions are limited to a few studies. An early measurement of Vp and Vs in a meltbearing peridotite reported no significant effect of melt fractions below 3.0 vol. \% [Sato et al., 1989]. The measurements based on torsional forced oscillation of melt-bearing olivine indicate reduced seismic velocities, and high attenuation can be observed for melt fractions as low as 0.01 
vol.\% [Faul et al., 2004], suggesting a possible melt fraction of 0.1 to 1 vol. \%, for the average grain size variation in the upper mantle from 1 and $10 \mathrm{~mm}$, respectively. The recent experimental developments allow accurate determination of seismic velocity measurements of partially molten rocks at the pressure and temperature conditions expected at the Earth's interior [Chantel et al., 2016] and predicted about 0.2 vol. \% melt content in the asthenosphere. On the contrary, the melt fraction estimations based on the acoustic velocity of analogue systems [Takei, 2000] indicate significantly higher melt fractions than those predicted using realistic upper mantle melts [Faul et al., 2004; Chantel et al., 2016]. For example, the $6.6 \%$ melt required to explain $10 \%$ Vs reduction in Borneol-diphenylamin analogue system [Takei, 2000] is considerably higher than the about $1 \%$ melt required by basaltic melt to explain a similar velocity reduction [Chantel et al., 2016].

The dependence of acoustic wave velocities and attenuation upon melt fraction and grainscale melt distribution has also been discussed in several theoretical studies. These studies were based on ideal melt geometries and explained using the oblate spheroid model [Schmeling, 1986], tube model [Mavko, 1980], the crack model [O’Connell and Budiansky, 1974] and models based on grain boundary wetness or "contiguity” [Takei, 1998, 2002; Yoshino et al., 2005; HierMajumder, 2008]. The calculations based on the finite element method on melt geometries led [Hammond and Humphreys, 2000] to conclude more than $1 \%$ melt is required to explain $3.6 \%$ and $7.9 \%$ velocity reduction for $\mathrm{Vp}$ and Vs respectively, which is significantly lower than the $6.2 \%$ and $11 \%$ reductions observed in laboratory measurements [Chantel et al., 2016]. The naturally occurring, randomly distributed melt [Faul et al., 2004; Chantel et al., 2016] is shown to have a significant effect on seismic velocity compared to the simplified melt textures assumed in theoretical models [Hammond and Humphreys, 2000; Takei, 2002; Yoshino et al., 2005] or 
analogue systems [Takei, 2000]. The considerably higher melt volume fractions required in theoretical models can be attributed to the idealized geometries, such as planar cracks, spheres, ellipsoids, or simplified cuspate forms, which may not represent the true melt geometries in naturally occurring melt [Kohlstedt, 1992; Faul et al., 1994; Hammond and Humphreys, 2000], limiting their applications to partially molten regions in the asthenosphere.

An early electrical conductivity measurement on basaltic melt suggested 5-10 vol. \% melt needed to account for the observed electrical anomalies in the asthenosphere [Tyburczy and Waff, 1983]. Similar amount of basaltic melt (5\%) also provided compatible values to geophysical observables with values up to $0.1 \mathrm{~S} / \mathrm{m}$ [Maumus et al., 2005]. However, recent studies suggest the presence of much lower volume fractions; 0.3-3.0 vol. \% for hydrous basaltic melt [Yoshino et al., 2010; Ni et al., 2011], or less than 0.3 vol. \% for carbonatitic melt [Gaillard et al., 2008; Yoshino et al., 2010]. The electrical conductivity of volatile enriched basalt (15-35 wt.\% $\mathrm{CO}_{2}$ and about 2-3 wt.\% $\mathrm{H}_{2} \mathrm{O}$ ) indicates about 0.1-0.15 vol.\% melt could explain the observed conductivity anomalies [Sifré et al., 2014]. The development of melt interconnectivity in partially molten rocks is known to have a profound effect on electrical conductivity [Waff, 1974, Maumus et al., 2005]. However, the number of studies investigating the influence of melt microstructures on EC is extremely limited. The study by [ten Grotenhuis et al., 2005] showed that a melt geometry evolving from isolated triple junction tubes at $0.01 \%$ of melt to a network of interconnected grain boundary melt layers at $0.1 \%$ of melt has a greater effect on electrical conductivity.

Various other experimental techniques have been used to constrain the melt fraction associated with the LVZ in the Earth's asthenosphere. Geochemical constraints from trace elements partitioning suggest that low degree of melting (less than $1 \%$ ) can be generated at 
greater depth (below than $100 \mathrm{~km}$ ) [Salters and Hart, 1989]. Similarly, studies based on experimental petrology, such as volatile $\left(\mathrm{H}_{2} \mathrm{O}\right.$ and $\left.\mathrm{CO}_{2}\right)$ effect on peridotite solidus, indicate the melt fraction in the asthenosphere LVZ has to be 0.1 vol. \% or less [Plank and Langmuir, 1992, Dasgupta and Hirschmann, 2007].

Both experimental and theoretical models acknowledge that the volume fraction and spatial distribution of melt play an integral part in modifying the seismic and electrical properties of partially molten rocks. However, large discrepancies still remain in the laboratory estimations (regardless of the technique) of the amount of melt volume fraction present in the asthenosphere [Pommier and Garnero, 2014; Karato, 2014]. Due to the large number of studies addressing the electrical properties of melt, the disagreement between laboratory-based electrical conductivity measurements is highly visible [Karato, 2014]. The influence of volatile contents could be one of the key parameters controlling the conductivity of the resulting melt [Yoshino et al., 2010; Ni et al., 2011; Sifré et al., 2014]. A model based on chemical variation in the melt has been proposed to explain the apparent disagreement on melt fraction estimations between electrical conductivity measurements and seismic models [Pommier and Garnero, 2014]. The discrepancy may primarily stem from the absence of systematic experimental investigation into the structural factors influencing the EC in partially molten systems. The effect of melt fraction on seismic velocity has been mostly limited to numerical models. Significant disagreement between these theoretical models is still present due to the choice of melt geometries [Yoshino et al., 2005]. A comparison with recent laboratory-based seismic velocity measurements on realistic partially molten materials [Chantel et al., 2016] indicates a significant underestimation of seismic response by theoretical models [Takei, 2000; Yoshino et al., 2005]. The cross-correlation of melt 
fraction estimations based on theoretical seismic models and laboratory electrical conductivity is at present a highly uncertain exercise.

The effect of melt texture and chemical compositions (volatiles) have long been assumed for the observed inconsistency, but there has never been a systematic study on how the evolving melt textures influence the electrical conductivity and seismic velocity (SV). Similar, melt textures and melt contents during high pressure, high temperature experiments are strongly affected by the stress field and the temperature distribution within the sample and it is highly unlikely that two experiments would yield identical melt distributions.

In this study, we aim to investigate the effect of ongoing textural modification of partially molten peridotite analog on both electrical conductivity and sound wave velocity. Here we have developed a novel high-pressure multi-anvil cell design to investigate simultaneously the seismic and electrical properties of partially molten samples. Acoustic wave velocity (Vp and Vs) and EC are measured on an identical sample presenting the same temperature gradient, stress field and the chemical impurities, which all influence the melt content and the melt texture in partially molten high pressure samples. This critical improvement enables us to compare the seismic and electrical responses to the onset of melting, to different melt volume fractions and to the evolution of melt interconnectivity of a partially molten sample. Based on our observations, we suggest possible scenario which may resolve the observed discrepancy of melt fraction estimations based on EC and SV measurements. 


\section{Methods}

\subsection{Sample preparation}

Samples used in this study were a powder mixture of natural San Carlos (SC) olivine and volatile-rich natural MORB glass (location $6^{\circ} 44^{\prime} \mathrm{N}, 102^{\circ} 36^{\prime} \mathrm{W}$, collected during the Searise-1 research cruise). The volatile content is estimated to be $2730( \pm 140)$ ppm wt. $\mathrm{H}_{2} \mathrm{O}$ and $165( \pm 40)$ ppm wt. $\mathrm{CO}_{2}$ [Andrault et al., 2014], comparable with the average $\mathrm{H}_{2} \mathrm{O}$ and $\mathrm{CO}_{2}$ levels observed in MORB from diverse geological settings [Naumov et al., 2014]. The MORB glass and inclusion free, hand-picked, SC olivine crystals were crushed separately and reduced to fine grain powders (see grain size distribution in figure S1). The water content analysis of the San Carlos olivine indicates less than 1 wt. ppm of water [Soustelle and Manthilake, 2017]. These powders were then mixed in predetermined weight proportions to obtain the desired melt fractions at high temperature. The accurate determination of melt fraction using the image analysis is an uncertain exercise. The mixing of MORB with olivine results in an accurate control of the melt fraction in the sample as the MORB component melts instantaneously above its melting temperature, which is significantly lower than the olivine solidus. This procedure has been extensively used to obtain a controlled melt fraction in high-pressure experiments [Faul et al., 1994; Cmíral et al., 1998; Maumus et al. 2005; Yoshino et al., 2010; Caricchi et al., 2011; Zhang et al., 2014; Chantel et al., 2016]. While this technique is suitable for obtaining controlled melt fractions (nominal melt fractions) in laboratory experiments, it cannot be used as a substitute for the physical property measurements of incipient melting scenarios [Sifré et al., 2014]. We prepared different starting materials with MORB volume fractions of $0.1,0.5,1$ and 2 vol. \% mixed with San Carlos olivine. The powder mixtures were ground with an automatic agate mortar for more than 2 hours to obtain a homogeneous distribution of the MORB 
component. The starting powder average grain size was estimated to be $3.74 \pm 3.32 \mu \mathrm{m}$ (Fig.

S1). In order to achieve high accuracy during weighting the powder, we prepare more than $5 \mathrm{~g}$ for each composition. The resulting powder mixtures were then hot pressed at $2.5 \mathrm{GPa}$ and 1100 K for 2 hours using a 1500 ton multi-anvil apparatus. The low temperature for hot pressing experiments (below the melting temperature of MORB) ensures that the starting materials are melt free and thus that the evolution of melt texture occurs during the conductivity and velocity measurements.

\subsection{High-pressure high-temperature experiments}

High-pressure, high-temperature experiments were performed using a 1500 ton Kawaitype multi-anvil apparatus at Laboratoire Magmas et Volcans, Clermont-Ferrand, France. For experiments conducted at $2.5 \mathrm{GPa}$, we used octahedral pressure media composed of $\mathrm{MgO}$ and $\mathrm{Cr}_{2} \mathrm{O}_{3}$ (5 wt. \%) in an 18/11 multi-anvil configuration (octahedron edge length / anvil truncation edge length) (Fig. 1). The assembly was designed to accommodate the geometrical requirements for measurements of Vp, Vs and EC in a single high pressure cell. The pre-synthesized cylindrical sample was inserted into a hexagonal boron nitride (hBN) capsule. The use of highpurity hBN sintered at high temperature and pressure without binder (Type - BN HP, FINAL Advanced Materials) prevents the $\mathrm{B}_{2} \mathrm{O}_{3}$ reacting with the silicate melt. The hBN capsule also helps to electrically insulate the sample with respect to the furnace. The furnace is composed of a $50 \mu \mathrm{m}$ thick cylindrical Re foil, with apertures for the electrode and the thermocouples wires. A zirconia sleeve was placed around the furnace to act as a thermal insulator. Oxygen fugacity of the sample was not controlled during the experiments, but should be below $\mathrm{Re}-\mathrm{ReO}_{2}$ buffer. 
We placed two electrodes made of Re discs (25 $\mu$ m thick) at the top and bottom of the

cylindrical sample. A tungsten-rhenium $\left(\mathrm{W}_{95} \mathrm{Re}_{5}-\mathrm{W}_{74} \mathrm{Re}_{26}\right)$ thermocouple junction was placed at one end of the sample to monitor the temperature. On the opposite side it was connected to a single $\mathrm{W}_{95} \mathrm{Re}_{5}$ wire (See Fig. S2 for details on electrode connection). We collected impedance spectra between the two $\mathrm{W}_{95} \mathrm{Re}_{5}$ wires. Cylindrical MgO ceramic sleeves were used to insulate the electrode wires from the furnace. A dense $\mathrm{Al}_{2} \mathrm{O}_{3}$ buffer rod was placed between one of the tungsten carbide (WC) anvil truncations and the sample to enhance the propagation of elastic waves and to provide sufficient impedance contrast to reflect ultrasonic waves at the buffer rodsample interface. Both ends of the anvil, the alumina buffer rod and the samples were mirror polished using $0.25 \mu \mathrm{m}$ diamond pastes in order to enhance mechanical contacts. All ceramic parts of the cell assembly, including the pressure media, were fired at $1373 \mathrm{~K}$ prior to the assembling in order to remove any absorbed moisture.

\subsection{Acoustic wave velocity measurements}

Acoustic wave velocities of samples were measured using the ultrasonic interferometry technique [Chantel et al., 2016]. In this method, electrical sine wave signals of $20-50 \mathrm{MHz}$ (3-5 cycles) with $V_{\text {peak-to-peak }}$ of 1-5 V were generated by an arbitrary waveform generator (Tektronix AFG3101C) and were converted to primary $\left(V_{P}\right)$ and secondary $\left(V_{S}\right)$ waves by a $10^{\circ} \mathrm{Y}$-cut $\mathrm{LiNbO}_{3}$ piezoelectric transducer attached to the mirror polished truncated corner of a WC anvil. The resonant frequency of the transducer is $50 \mathrm{MHz}$ for compressional waves ( $P$-waves) and 30 $\mathrm{MHz}$ for shear waves ( $S$-waves). Elastic waves propagated through the anvil, the alumina buffer rod (BR) and the samples, and were reflected back at the anvil-BR, BR-sample, and sampleelectrode interfaces. We also consider possible reflections from the Re electrodes [Davies and 
O'Connell, 1977; Jackson et al., 1981; Niesler and Jackson, 1989] (Text S1 c). The reflected elastic waves were converted back to electrical signals by the transducer and captured by a Tektronix DPO 5140 Digital Phosphor Oscilloscope at a rate of $5 \times 10^{9}$ sample/s. Signals at 20, 30, 40 and $50 \mathrm{MHz}$ were recorded at each temperature step. The two-way travel time for the acoustic waves propagating through the sample can be determined by the time difference between the arrivals of the echoes from the BR-sample interface and the sample-electrode interface by the pulse-echo overlap method [Kono et al., 2012].

\subsection{Electrical conductivity measurements}

EC measurements were performed using the ModuLab MTS Impedance/Gain-phase analyzer in the frequency range of $10^{6}-10^{1} \mathrm{~Hz}$. Polyphasic samples are characterized by a combination of resister-capacitor/constant phase element (R-C/CPE) circuits and the resistance can be obtained by fitting the impedance spectra to appropriate equivalent circuits (Fig. S3). Once the sample resistance has been determined, conductivity can be calculated using the sample dimensions determined at each temperature using the thermal expansion of the constituent phases. The insulation resistance of the assembly was determined in a preliminary experiment using an hBN rod at similar pressure-temperature conditions and was observed to be lower than the sample resistance.

At the target pressure of $2.5 \mathrm{GPa}$, the sample was kept at $500 \mathrm{~K}$ for more than 12 hours.

While maintaining $500 \mathrm{~K}$, the electrical resistance of the samples, measured at regular intervals, usually increases due to the removal of the moisture absorbed by the sample and surrounding materials. This step is crucial to prevent the moisture $\left(\mathrm{H}_{2} \mathrm{O}\right)$ being incorporated into the sample at higher temperatures [Manthilake et al., 2009]. The next heating cycle started once the resistance 
reached a steady value, which is often 1-2 orders of magnitude higher than the resistance measured at the beginning of the heating cycle. We generally performed several heating-cooling cycles at temperature steps of 50-100 K, until sample resistance was reproducible between the heating and cooling paths. This procedure minimizes the uncertainty of EC measurements due to impurities $\left(\mathrm{H}_{2} \mathrm{O}\right.$ and $\left.\mathrm{CO}_{2}\right)$. Once the solid sample EC was reproducible (without moisture), the temperature was gradually increased in smaller temperature steps ( $25 \mathrm{~K}$ ) to initiate melting. Sample melting is characterized by a drastic decrease in the sample resistance (increase in conductivity). Finally, the temperature was kept constant at $1650 \mathrm{~K}$ and impedance spectra were collected at regular intervals for more than 1 hour.

\subsection{Melt textures and dihedral angle measurements}

Micro-textures of the recovered samples were investigated with a Field Emission Gun Scanning Electron Microscope (FEG-SEM) with an accelerating voltage of $15 \mathrm{kV}$ and working distance of 9 - $11.6 \mathrm{~mm}$. High magnification back scattered electron (BSE) images were obtained in order to identify the degree of interconnectivity and the structure of the melt at the grain boundaries in partially molten samples after SV and EC measurements. The presence of the hard alumina piston may introduce differential stresses to the sample, resulting in a shape-preferred orientation (SPO) in partially molten samples [Bussod and Christie, 1991]. To characterize the possible melt alignment in an olivine matrix, we performed image analyses on BSE images along a section parallel to the axis of the cylindrical sample. The orientation of the long axis of melt pockets and area of the melt pockets were obtained by image processing techniques using Matlab software (Fig. S4). 


\subsection{Grain size and grain orientation distribution}

The grain size of our samples was estimated using two different techniques: the intercept method, and using FOAMS software [Shea et al., 2010]. The intercept method estimates the number of intersections of grain boundaries with a random line drawn across the sample. The length of the line is important in order to statistically cross enough grains. The FOAMS software measures every isolated particle from skeletonized images and estimates its morphological parameters: area, perimeter, shape from 2D ellipse with a long and short axis, etc. The program also calculates 2D parameters such as aspect ratio and elongations. From the binary images, the code can convert 2D morphological information into 3D information using the equivalent diameter for spherical geometry by means of stereological conversion equations from [Sahagian and Proussevitch, 1998]. This program works properly for all type of samples for 2D information. Volumetric estimations (2D to 3D) can be performed when the grains are mostly rounded and do not show strongly elongated shapes. Results are given in table S1.

\subsection{Experimental uncertainties}

Experimental measurements of Vp, Vs and EC are subjected to uncertainties originating from the estimation of temperature pressure, sample dimensions and fitting errors. Errors have been estimated to be $2.5 \%$ for seismic velocities $(2 \sigma), 5 \%$ for velocities drops $(2 \sigma)$ and $5 \%$ for EC values $(2 \sigma)$. Errors on the melt fractions are less than $1 \%$ relative (ex: $1 \pm 0.01 \%$ of MORB). Detailed sources of uncertainties for each technique and error propagation calculations are given in supporting information (Text S1) [Bouhifd et al., 1996; Gillet et al., 1991; Li et al., 2007]. Error bars are reported in each figure when larger than the symbol size except figure 4 and $8 a$ ) for visibility. 


\section{Results}

319

\subsection{Acoustic velocity}

The acoustic wave velocities obtained for samples containing SC olivine and $0.1,0.5,1$ and $2 \%$ nominal volume fractions of melt are shown in figure 2. Below the melting temperature, Vp and Vs decrease with increasing temperature, emphasizing the characteristic decrease of bulk and shear modules with temperature. Upon melting of the MORB component, which is at about $1590 \mathrm{~K}$, both Vp and Vs decrease significantly for the samples with 0.5 to $2 \%$ MORB. The magnitude of the velocity drop is positively correlated to the MORB fraction in the sample, but no significant change is observed at the melting temperature for pure olivine and the sample with 0.1 vol. \% melt. After the initial decrease in response to the MORB melting, the acoustic velocities Vp and Vs remain unchanged while maintaining the sample at a constant temperature of $1650 \mathrm{~K}$.

\subsection{Electrical conductivity}

The electrical conductivity of samples containing $0.1,0.5$ and 2 vol. \% of nominal melt fractions are shown in figure 3. At the melting temperature of MORB ( 1590 K), the samples with 0.5 to 2 vol. \% melt indicate sudden increases in conductivity (up to a factor of 5), compared to their solid counterparts. However, no immediate change in conductivity is observed for 0.1 vol. \% melt upon crossing the temperature threshold. EC of all melt-bearing samples continues to increase after the melting event, while being kept at a constant temperature of 1650 K. The rate of increase of conductivity gradually decreases with time (Fig. 3), probably approaching a steady-state with time, however these 1h duration experiments didn't reached a stable EC value over time. The conductivity values after being kept at $1650 \mathrm{~K}$ for more than 30 
minutes indicate an increase in conductivity of 0.6 log units, a factor of 3.98, for the $0.1 \%$ melt sample compare to the value obtained before melting. The conductivity variations after being kept for more than 50 minutes at $1650 \mathrm{~K}$, are about $0.6 \log$ units, a factor of 3.98, for the $0.5 \%$, and a $0.4 \log$ units, a factor of 2.51, for the $2 \%$ melt-bearing samples.

\subsection{Textural analyses of samples and melt}

The presence of melt is clearly visible for all samples, with melt distributing along the grains boundaries as well as triple junction tubes. Interconnected melt networks are visible over a large part of each sample including the samples with 0.1 vol. \% of melt (Fig. 4). Using the high resolution SEM images, we determined the wetting angles of the melt-solid interfaces, which indicate a median angle of $27 \pm 4^{\circ}$.

Table S1 presents the grain size and grain orientation parameters derived from both intercept and FOAMS software, samples average grain size are similar and between 7 to 15 micrometres. The eccentricity is calculated from the best fitting ellipse foci and circle centre. This parameter indicates how far the best fitting ellipse deviates from perfect circularity, the values from 0.76 to 0.84 in our samples indicate that grains are mainly rounded but not perfect spheres. Elongation parameter is expressed by $\varepsilon=(a-b)(a+b)$, which characterizes the difference between the long (a) and short (b) axes of the fitting ellipse; large values (close to 1) indicate elongated particles. Our average values trends from 0.25 to 0.36 , meaning grains have an elliptic cross section which slightly deviates from circularity. Aspect ratio is expressed as A = b/a, and characterizes the shape of the particle; large aspect ratios (close to 1) indicate particles are rounded and not elongated; our high-intermediate values are good agreement with this observation. 
The analyses based on the orientation of the long axis of melt pockets indicate random distribution of melt within the olivine matrix (Fig. S4). The associated histogram indicates no significant preferential orientation.

\section{Discussion.}

\subsection{Effect of evolving melt texture on acoustic wave velocity and electrical conductivity}

Upon melting, partially molten samples evolve toward textural equilibrium with time, thus improving the melt interconnectivity and melt redistribution within the olivine matrix (Fig. 4). The comparison of images of samples before melting and after keeping prolonged time above the melting temperature of MORB clearly demonstrate the evolution of Ol+MORB powder mixture from initial non-equilibrium state (MORB is randomly distributed) to the extensive wetting of crystal faces and the smoothly curved solid-melt interfaces (Fig. S5). The textural equilibrium depends on several factors such as melt fraction, melt chemistry and grain size distribution [Laporte and Provost, 2000]. The melt geometries in olivine-basalt systems consist of grain boundary melt layers, triple junction networks [Yoshino et al., 2005, 2009] and ellipsoïdal discs [Faul et al., 1994]. The continuous increase of EC observed in our experiments can be attributed to the gradual development of an interconnected network of melt channels, which facilitate the movement of charge carried through the melt. In contrast, acoustic wave propagation in a partially molten media should be more affected by the presence of melt in its path (volume fraction), than its fine geometrical evolution subsequent to melt interconnection. We note that the EC increased quickly in the first tens of minutes and showed a flat evolution with almost flat slope after about 1 hour, indicating that the textural modifications that influence the interconnectivity of the melt can be mostly achieved within few hours. The melt takes its 
final like shape very quickly (in the first hour), however complete equilibration between melt and host olivine matrix in both chemical and textural aspects require several weeks of annealing [Waff and Blau, 1982; Laporte and Provost, 2000].

\section{a) Interpretation of acoustic wave velocity results}

The magnitude of the drop in seismic wave velocity in response to melting is proportional to the melt volume fraction in the sample (Fig. 2). Compared to the higher melt fractions, the sample containing $0.1 \%$ melt does not show abrupt variations of acoustic wave velocity in response to the onset of melting of MORB components. This observation suggests that the volume fraction of melt has to be sufficiently large (higher than 0.1 vol. \%) in order to alter the seismic wave propagation through partially molten rock. Also, associated errors to seismic wave velocity measurements and fitting does not allow distinguishing significant drop for low melt fractions $(\sim 0.1 \%)$. Further, the relatively constant seismic velocity at a constant temperature of $1650 \mathrm{~K}$, after the melting of MORB, suggests that the seismic velocity is less sensitive to the ongoing textural equilibration of the sample. The melt fraction in a partially molten rock with complete wetting properties is observed to be the key parameter controlling the magnitude of seismic velocity in geological systems. The secondary waves (Vs) are more sensitive to the presence of melt due to their near zero shear modulus, which further enhances their ability to detect and quantify melting in laboratory samples.

The comparison of present data with previous experimental and theoretical estimations of seismic velocity is shown in figure 5. While our results are consistent with that of [Chantel et al., 2016], there are considerable deviations in our experimental values from those estimated based on theoretical approximations [Takei, 2000]. As explained previously, the disagreement may arise 
due to the simplified melt geometries assumed in theoretical models. This observation can be further corroborated by comparing two theoretical models, one based on natural melt geometries [Yoshino et al., 2005], and the other on ideal melt geometries [Takei, 2000]. The model with melt arrangements similar to naturally occurring melt record a significant velocity drop for a given melt fraction compared to the one assuming ideal melt distribution. However, the model based on grain boundary wetness [Yoshino et al., 2005] also predicts the seismic velocities are significantly affected by modifications on the pore geometry. It has been shown that the melt wetting properties vary significantly with increasing pressure and volatile content [Yoshino et al., 2007]. The slight discrepancy between the present study and that of [Yoshino et al., 2005] can be explained by the change in wetting properties, due to improved melt wetting properties at high pressure and the presence of both $\mathrm{H}_{2} \mathrm{O}$ and $\mathrm{CO}_{2}$ in our samples.

\section{b) Interpretation of electrical conductivity results}

The electrical conductivity variation while kept at constant temperature (at $1650 \mathrm{~K}$ ) provides valuable insights into the development of interconnected melt channels in partially molten samples. For larger melt fractions (above $0.1 \%$ ) the melt network forms efficiently as shown by an order of magnitude conductivity increase observed at the onset of melting. However, after the onset of melting and the associated EC jump, while kept at constant temperature of $1650 \mathrm{~K}$, the increase in electrical conductivity for larger melt fractions (2 \% with $0.4 \log$ unit increase of EC) is smaller than the sample with a low melt fraction $(0.1 \%$ with 0.6 log unit increase of EC). This potentially indicates that when the melt fraction is sufficiently large, the major portion of melt is already arranged into a well distributed network of melt channels. On the other hand, the subsequent modifications improving the melt interconnectivity 
433 have a significant effect on low melt fractions. It has been shown that the melt geometry in a 434 mineral-melt aggregate is determined by the solid-solid and solid-liquid interfacial energies 435 [Laporte and Provost, 2000]. The solid-liquid interfacial energies may control the 436 interconnectivity of a partially molten medium at low melt fraction; the network of melt could be 437 limited in its 3D extension between the olivine grains, with some surfaces remaining initially un438 wetted due to surface tension.

As for acoustic velocity, a sharp variation in electrical conductivity was not immediately

440

apparent for the sample with $0.1 \%$ melt fraction. However, when maintained at $1650 \mathrm{~K}$, EC continued to increase for the $0.1 \%$ melt sample, after 1 h to 0.6 log unit higher than the conductivity of the sample before melting. This observation suggests that the electrical conductivity method can be used to detect melt fractions lower than $0.1 \%$ as long as the measurements are performed on texturally equilibrated samples. As well, EC is very sensitive to the onset of melting with few orders of magnitude of increase after only few minutes. Reading value of sample resistance (direct measurement to infer EC) is instantaneous and can be a powerful tool to detect the onset of melting during an experiment.

The electrical conductivity of similar olivine-basalt systems has been investigated in previous experiments [Maumus et al,. 2005, Yoshino et al., 2010; Caricchi et al., 2011; Zhang et al., 2014, Laumonier et al., 2017] (Fig. 5). While measured conductivities are located within the individual EC measurements of olivine [Constable, 2006, Laumonier et al., 2017] and basaltic melt [Presnall et al., 1972; Tyburczy and Waff, 1983; Ni et al., 2011, Laumonier et al., 2017], the partially molten systems do not display good agreement between different studies. The slightly higher EC observed for partially molten samples in [Yoshino et al., 2010], compared to our study may have been due to their use of texturally equilibrated melt-bearing samples (pre-synthesized 
samples in a piston cylinder apparatus) in electrical conductivity measurements, which compare favourably with our observations. Values comparable to "equilibrated samples” conductivities can be retrieved, by using extrapolation of our EC versus time trend, for timescales of days or weeks, indicating full equilibration might require might require a significant time (Fig. 5 and 6). This again, underlines the crucial importance of the use of equilibrated EC values for safe comparisons.

\subsection{The source of discrepancy}

The interpretation of seismic and electrical anomalies in terms of melt fraction often results in conflicting estimations as to the extent of melting in the asthenosphere [Pommier and Garnero, 2014; Karato, 2014]. A conductivity model based on major element chemistry of melt attributed the apparent inconsistencies in conductivity measurements to possible chemical variations in the melt [Pommier and Garnero 2014]. Their model predicts that low degree melting of peridotite produces melt that is more conductive than basaltic compositions. We find their approach is an important step towards unifying the seismic and electrical observations. However, the melt fractions estimations used in their study were based on theoretical models, which appear to underestimate the effect of melt fraction on seismic velocity. Monitoring the behaviour of melt-bearing samples for an extended period of time at high pressure and high temperature remains a challenging exercise. Escape of melt during prolonged heating is one of the major sources of failure, and experimental studies often overcome this issue by shortening the duration of the in situ measurements at high temperature. However, our results demonstrate that the EC values can vary significantly with time within the first hour of measurements, and relatively stable EC values can be obtained once the 3D interconnected network has been established. Texturally non-equilibrium melt can lead to an underestimation of 
the total effect on EC of a given melt fraction (Fig. 6). Comparison of such measurements with geophysical profiles, therefore, results in an overestimation of the melt fraction in the corresponding region in the Earth's mantle. Values here provided after $1 \mathrm{~h}$ at $1650 \mathrm{~K}$ are not fully stabilized as highlighted by the subtle slope of the fit. We also note that once the sample conductivity stabilized, as a result of improved melt interconnectivity, electrical conductivity values of samples containing $0.1,0.5$ and $2 \%$ are not considerably different (less than one order of magnitude). This difference becomes subtle, close to the uncertainty of measurements, for higher melt fractions according to the trend shown in figure 6. This implies that uncertainties on inferred melt fractions from EC can be very important if implied melt fractions are higher than few percents. This observation is particularly crucial for magnetotelluric (MT) profiles with low spatial resolution. For these reasons, EC values here provided will not be further used for geophysical implications. However, we note that the electrical conductivity measurements are superior over acoustic wave velocity for detecting low melt volume fractions for samples with evolved melt textures. If the wetting properties of the melt are modified by the presence of significant amounts of volatiles in the melt $\left(\mathrm{H}_{2} \mathrm{O}\right.$ and $\left.\mathrm{CO}_{2}\right)$ the electrical response for low melt fractions is instantaneous [Sifré et al., 2014].

In this study, we observe real-time $\mathrm{Vp}$, Vs and EC responses during melting and consecutive textural evolution of melt. The variation of electrical conductivity subsequent to the melting of MORB can also be caused by the chemical changes occurring at high temperatures for a prolonged period of time. The effect of change in chemical composition on electrical conductivity in melt has been investigated in previous studies [Roberts and Tyburczy, 1999], with a general trend showing an increase in conductivity with increasing alkali and $\mathrm{Fe}+\mathrm{Mg}$ contents and a decrease with increasing silica content. However, we observe that the melt composition 
stays similar to the starting MORB composition during the experiments, except for a minor decrease in Fe content (Table 1). The Na is an important charge carrier in silicate melt [Pfeiffer, 1998; Gaillard and Iacono-Marziano, 2005; Ni et al., 2011] and Na contents in our melt remains similar to the starting composition. Based on the totals of chemical analyses of melt, we confirm that significant volatile enrichments may not occur in our melt. Therefore, the observed conductivity increase with time is not expected to be caused by any chemical modification to the melt. This observation also confirms that the final melt fraction in the sample stays similar to the starting material. Similarly, due to the low partition coefficient between olivine and melt ( 0.004) [Novella et al., 2014], the water is mostly retained by the melt phase, so proton $\left(\mathrm{H}^{+}\right)$ diffusion in olivine affecting the electrical conductivity at high temperature can also be ruled out. The constant velocity after the melting of MORB components also rules out the possible increase in melt fraction in the sample at constant temperature, which is also supported by image analysis and chemical mapping of the sample. Further, analyses on the orientation of the matrix and melt pockets in our samples indicate random shape preferred orientation (SPO) ruling out melt channelling due to possible anhydrostaticity in the high-pressure cell assembly (Fig. S4).

\subsection{Applications of laboratory results to the Earth's interior}

The comparison between laboratory data and seismological signals requires experiments in which the molten phase is in textural equilibrium with the solid matrix. Due to time-limited laboratory experiments, transient conditions may affect the results of acoustic velocities. In this case, textural analysis is important for correct interpretation of experimental data and run products. In a partially molten system at given pressure and temperature, the melt network can evolve to minimize the energy of melt-solid interfaces. This equilibration process concerns the 
wetting angle $\theta$ at solid-solid-melt triple junctions, the area-to-volume ratio of melt pockets at grain corners and the melt permeability threshold [Laporte et al., 1997]. The small dihedral angles estimated for our partially molten samples ensures complete grain boundary wetting and melt interconnectivity even for extremely low melt volume fractions [von Bargen and Waff, 1986; Laporte et al., 1997; Laporte and Provost, 2000], which is crucial for propagation of seismic waves. The solid-melt dihedral angle is known to vary with pressure, temperature and with the composition of the melt phase [Minarik and Watson, 1995; Yoshino et al., 2005]. Experimental studies suggest that textural equilibration is a time-dependent process, which usually requires long annealing times (weeks or months) [Waff and Blau, 1982; Laporte and Provost, 2000, Maumus et al., 2005]. Still, small dihedral angle (10-30), the extensive wetting of crystal faces and the smoothly curved solid-melt interfaces observed in our samples are strong indications that the microstructure has reached transient conditions and forming a melt solid network close to equilibrium textures [Cooper and Kohlstedt, 1984; Waff and Faul, 1992; Cmíral et al., 1998] (Fig.4). Further, after reaching the peak temperature, the acoustic velocity remains nearly constant (Fig. 2), suggesting that the samples are well relaxed, enabling a safe comparison of our seismic wave velocity measurements with geophysical observations.

In addition, the extrapolation of laboratory acoustic wave velocities measurements to natural observations require the consideration of both anelasticity and frequency effects. Laboratory experiments (when not torsional) are usually performed at the frequency range from 20 to $50 \mathrm{MHz}$. The choice of this frequency range is determined by both requirements on excitation frequencies for the piezo-electric transducer as well with the restricted size of the probed samples in HP-HT apparatus. 
Both anelasticity and anharmonicity that are accounting for the temperature dependence 548 of sound velocity could lower the observed velocities. These are functions of frequency,

549

temperature, pressure, mineral/melt intrinsic properties (including the chemical composition) as well as grain-size and grain boundaries micro textures [Rivers and Carmichael, 1987; Karato, 1993; Jackson et al., 2002, 2004; Faul et al., 2004]. In solids, anharmonic effects related to thermal expansion $(\partial \rho / \partial \mathrm{T})$ were found to be important in high frequency $(\mathrm{MHz})$ experiments. This process does not imply energy loss and remains nearly insensitive to frequency [Karato, 1993]. On the other hand, anelasticity is associated to energy loss and depends on frequency and relaxation effects. Relaxation effects are thermally activated, hence anelasticity must be accounting for a significant part of the attenuation at high temperatures. Anelasticity of partially molten system have been poorly studied [Faul et al., 2004; Jackson et al., 2004]. Because our melt fractions are small $(\leq 2 \%)$ and similar to melt fraction estimated in the mantle, the assumption of using anelastic values of pure olivine is reasonable [Jackson et al., 2002; Chantel et al., 2016], also partially molten systems were found to have similar grain boundary sliding process to solid [Jackson et al., 2002; Faul et al., 2004]. Nevertheless, this process is more easily activated in melt bearing samples, where weaker grain boundaries have been reported [Faul et al., 2004]. In addition, most of silicate melts have very high absorption in this frequency range and signals are seriously attenuated [Rivers and Carmichael, 1987]. However, this study showed that the echo overlap technique is suitable for high-Q melts, and thus appropriate for MORB melts. This study also stressed that for low viscosity melts ( $<1000$ Pa.s), which is the case of MORB melts at high temperature (presence of volatiles will significantly increase this effects), velocities are independent from frequency, as expected when wave's period is much smaller than the characteristic relaxation time $(1 / \mathrm{f}<<\tau)$. Relaxation time was estimated using the relation $\tau=$ 
$0.01^{*} \eta^{*} \beta$, where $\beta$ is the inverse of adiabatic compressibility and $\eta$ the melt viscosity, used for fitting of theoretical and experimental dispersion curves by Rivers and Carmichael, (1987). Calculation using their parameters for the Kilauea basalt (1700 K) yields relaxation time of 0.467 nanoseconds for frequency of $30 \mathrm{MHz}$ (used in our study). The product of angular frequency by relaxation time between $10^{-2}$ and $10^{-1}(0.088)$ can be converted into a $\mathrm{C} / \mathrm{C}_{0}$ ratio (see fig 10 therein). It estimates the measured velocity to be similar to the relaxed one as the ratio is very close to unity $\left(1 \leq \mathrm{C} / \mathrm{C}_{0}<1.10\right)$, pointing a very small effect of anelastic behavior. Our moderately hydrous MORB probably have a lower viscosity and accordingly a shorter relaxation time favoring our conclusions.

Detailed discussion on quality factor (Q) estimation by ultrasonic experiments, on similar compositions, has already been made by Chantel et al., (2016). However, our $\partial \ln (\mathrm{Vp}) / \partial \mathrm{T}$ and $\partial \ln (\mathrm{Vs}) / \partial \mathrm{T}$ values of -4.95 and $-8.78\left(* 10^{-5}\right) \mathrm{K}^{-1}$, of our olivine + MORB samples prior melting, are somewhat similar with temperature dependence values calculated by high Q from Karato, (1993), indicating a good agreement with pure olivine data up to melting point with anharmonic plus anelastic behavior.

Finally, the use of $\mathrm{MHz}$ frequencies tends to underestimate the effect of anelasticity. This increases our uncertainty on our measurements, but this uncertainty must be reasonable as shown by the small errors estimated in absorption calculations (4\%) [Rivers and Carmichael, 1987], as well with near relaxed sound speed found for melt. In this study, we thus report a minimal effect of the presence of partial melt on the acoustic wave velocities and consider similar bias as estimated for solids (anelasticity and anharmonicity) because small fraction of melt seems to have only a moderate effect. Our extrapolation suffers also from grain size considerations as 
592 detailed by Jackson et al. (2002), even though this process was found to be nearly frequency

593 independent for attenuation at mantle conditions.

$595 \quad 4.5$ Geophysical implications

Our study demonstrates that the melt content in a partially molten media can be better quantified by using the reduction of seismic velocity for melt fractions with a minimum detectable melt fraction between $0.5 \%$ and $0.1 \%$ (no seismic velocity drop seen for $0.1 \%$ ). On the other hand, for the studied melt fractions of 0.1-2.0 \% with well-developed interconnectivity, electrical conductivity, varies within a strict range of about 0.5 log units even if transient values were only reached, too narrow to resolve fine melt structures without introducing significant uncertainties.

In this study, we specifically use the \% drop in acoustic wave velocity as a measure to determine the melt fraction. Our study indicates that the 3-8 \% global reduction in seismic velocity (Vs) observed at the top of the asthenosphere [Anderson and Sammis, 1970; Widmer et al., 1991; Romanowicz, 1995] can be explained by 0.3-0.8 \% volatile-bearing melt (Fig. 7a). However, these values may vary laterally depending on the extent of melting at the corresponding temperatures and the volatile contents in the mantle [Sifré et al., 2014]. Regional Vs variations of up to $10 \%$ observed below the Pacific plate [Schmerr, 2012] indicate large melt fractions of up to $1 \%$ present in some parts of the asthenosphere, suggesting large heterogeneities in terms of melt distribution. Apart from the global reduction of seismic velocity, numerous studies report velocity perturbations in various geological settings such as spreading ridges, intraplate mantle plumes and subduction. [e.g. Pommier and Garnero, 2014]. Assuming melt chemistry does not have any significant influence on acoustic wave velocity [Rivers and 
Carmichael, 1987]; we compare our melt fraction estimations to those reported using theoretical models (Table S2).

In addition to the use of absolute sound wave velocities and velocities drop, the use of Vp/Vs ratio can be of significant interest for comparison with seismological data. Bulk and shear moduli of a partial melt system (a solid containing pore spaces saturated with melt) varies as a function of melt volume fraction. Accordingly, the relative change of $\mathrm{Vp} / \mathrm{Vs}$ ratio could indicate the presence of melt in deep mantle conditions. As detailed in Chantel et al., 2016, the absolute velocities values measured on analog systems do not compare well with real seismic velocities measurements. It is mainly due to the difference in mineralogy (e.g pure olivine against peridotites) and relaxation effects due to differences in frequencies between natural and experimental seismic velocities estimations (see discussion therein). However, the use of Vp/Vs ratios and its variations allow a relevant comparison of our analog data to natural system as changes are relative and not based on absolute velocities values.

Our data indicate that below melting point, $\mathrm{Vp} / \mathrm{Vs}$ ratio increases from 1.75 to 1.8 from room temperature up to $1650 \mathrm{~K}$ (Fig. 8). These values are consistent with values observed for solid upper mantle ranging from 1.7 to 1.8 given by standard models such as PREM [Dziewonski and Anderson, 1981] or AK135 [Kennett et al., 1995]. These values are also consistent with moderate $\mathrm{Vp} / \mathrm{Vs}$ values obtained from upper mantle minerals, ranging also between 1.7 and 1.8 for olivine (1.8), clino and othropyroxenes (1.72 and 1.74) at the same pressures [ $\mathrm{Li}$ and Liebermann, 2007]. At melting, we observe a strong and sudden increase of the Vp/Vs ratio. The magnitude of the increase correlates positively with the melt fraction. Vp/Vs ratios above 1.9 are observed for sample with $2 \%$ melt fraction (Fig. 8 c). Our Vp/Vs ratio values compare favorably with LVZ estimations with ratios given by global models ranging between 1.8 and 1.85 and 
requiring only moderate amount of melt ( $<1 \%$ of melt). However, our data implies very high melt fractions involved in local anomalies where $\mathrm{Vp} / \mathrm{Vs}$ ratios up to 2.5 or more have been reported [Schaeffer et al., 2010, Hansen et al., 2012]. These very high anomalies imply higher melt fractions ( $12.5 \%$ for $\mathrm{Vp} / \mathrm{Vs}$ ratio of 2.5 , based on the trend defined on Fig. 8 c) even if other physical processes such very high volatiles contents in melts could explain these anomalies.

In general, we find that the melt contents reported in previous geophysical studies are consistently higher than the estimations based on laboratory measurements of seismic wave velocities. The majority of these studies used the theoretical prediction of velocity reduction for partially molten rocks, which underestimate the effect of melt fraction on seismic velocity. The use of our laboratory measurements provides melt fractions that are consistent with petrological models. Further, we believe that the refined melt fraction estimations would provide a solid platform to constrain a meaningful cross correlation between field-based seismic and electrical observations. The effect of the chemical composition of melt on acoustic wave velocity is one of the important aspects worth exploring in future studies.

\section{Conclusions}

This study presents the first simultaneous measurements of electrical conductivity and acoustic wave velocity of partially molten samples of geophysical importance. The results highlight how electrical conductivity and acoustic wave velocity respond to the evolving melt texture from a completely random melt distribution. The continuous increase of electrical conductivity at constant temperature, after melting of MORB, indicates that the melt interconnectivity evolves with time. In contrast, constant seismic velocity after the melting 
suggests acoustic velocity is sensitive to the melt volume fraction in the sample, but less affected by the evolving melt texture. Our results suggest that the electrical conductivity of partially molten materials measured before reaching the evolved melt interconnectivity can lead to an underestimation of the EC for a given melt fraction. This may result in an over-estimation of melt fraction in geological settings. Overall, the Vs measurements appear to be a more appropriate method for determining the melt fraction in a partially molten system with complete wetting properties. The previous approximations based on theoretical models of seismic velocity appear to overestimate the extent of melting in the mantle. This study demonstrates the necessity of using electrical conductivity values from texturally equilibrated partially molten sample for comparison with geophysical data.

\section{Acknowledgments}

We thank J-M Henot for the SEM analyses, J-L Devidal for the electron microprobe analyses and A. Mathieu for the technical assistance. We thank F. Gaillard for beneficial discussions. DF acknowledges S Thivet for FOAMS assistance and starting powder analysis. GM acknowledges funding from the French PNP program (INSU-CNRS) and Actions initiatives OPGC 2014. DA is supported by ANR-13-BS06-0008. This research was financed by the French Government Laboratory of Excellence initiative nANR-10-LABX-0006, the Région Auvergne and the European Regional Development Fund. This is Laboratory of Excellence ClerVolc contribution number xx. All of the experimental data and numerical modelling are provided in the figures and tables obtained by methods described in the text. 


\section{References}

Anderson, D., and C. Sammis (1970), Partial melting in the upper mantle, Phys. Earth Planet. Inter., 3, 41-50.

Andrault, D., G. Pesce, M. A. Bouhifd, N. Bolfan-Casanova, J.-M. Hénot, and M. Mezouar (2014), Melting of subducted basalt at the core-mantle boundary., Science, 344(6186), 8925, doi:10.1126/science.1250466.

Bouhifd, M.A., D. Andrault, G. Fiquet and P. Richet (1996), Thermal expension of forsterite up to the melting point, Geophysical Research Letters,23: 1143-1146.

Bussod, G. Y., and J. M. Christie (1991), Textural Development and Melt Topology in Spinel Lherzolite Experimentally Deformed at Hypersolidus Conditions, J. Petrol., 17-39.

Caricchi, L., F. Gaillard, J. Mecklenburgh, and E. Le Trong (2011), Experimental determination of electrical conductivity during deformation of melt-bearing olivine aggregates: Implications for electrical anisotropy in the oceanic low velocity zone, Earth Planet. Sci. Lett., 302(1-2), 81-94, doi:10.1016/j.epsl.2010.11.041.

Cartigny, P., F. Pineau, C. Aubaud, and M. Javoy (2008), Towards a consistent mantle carbon flux estimate: Insights from volatile systematics $(\mathrm{H} 2 \mathrm{O} / \mathrm{Ce}, \delta \mathrm{D}, \mathrm{CO} 2 / \mathrm{Nb})$ in the North Atlantic mantle (14 $\mathrm{N}$ and $\left.34^{\circ} \mathrm{N}\right)$, Earth Planet. Sci. Lett., 265(3-4), 672-685, doi:10.1016/j.epsl.2007.11.011.

Chantel, J., G. Manthilake, D. Andrault, D. Novella, T. Yu, and Y. Wang (2016), Experimental evidence supports mantle partial melting in the asthenosphere, Sci. Adv., 2(5), e1600246, doi:10.1126/sciadv.1600246.

Cmíral, M., J. D. Fitz Gerald, U. H. Faul, and D. H. Green (1998), A close look at dihedral angles and melt geometry in olivine-basalt aggregates: A TEM study, Contrib. to Mineral. 
Petrol., 130(3-4), 336-345, doi:10.1007/s004100050369.

Constable, S. (2006), SEO3: A new model of olivine electrical conductivity, Geophys. J. Int., 166(1), 435-437, doi:10.1111/j.1365-246X.2006.03041.x.

Cooper, R. F., and D. L. Kohlstedt (1984), Sintering of Olivine and Olivine basalt Aggregates, Phys Chem Miner., 11, 5-16, doi:10.1007/BF00309372.

Dasgupta, R., and M. M. Hirschmann (2006), Melting in the Earth’s deep upper mantle caused by carbon dioxide, Nature, 440(7084), 659-662.

Dasgupta R, Hirschmann MM (2007) Effect of variable carbonate concentration on the solidus of mantle peridotite. Am Mineral 92:370-379. doi: Doi 10.2138/Am.2007.2201

Dziewonski AM, Anderson DL (1981) Preliminary reference Earth model. Phys Earth Planet Inter 25:297-356. doi: 10.1016/0031-9201(81)90046-7

Faul, U. H., D. R. Toomey, and H. S. Waff (1994), Intergranular basaltic melt is distributed in thin, elongated inclusions, Geophys. Res. Lett., 21(1), 29-32.

Faul UH, Fitz Gerald JD, Jackson I (2004) Shear wave attenuation and dispersion in meltbearing olivine polycrystals: 2. Microstructural interpretation and seismological implications. J Geophys Res B Solid Earth 109:1-20. doi: 10.1029/2003JB002407

Faul, U. H., J. D. Fitz Gerald, and I. Jackson (2004), Shear wave attenuation and dispersion in melt-bearing olivine polycrystals: 2. Microstructural interpretation and seismological implications, J. Geophys. Res. B Solid Earth, 109(6), 1-20, doi:10.1029/2003JB002407.

Fischer, K. M., H. A. Ford, D. L. Abt, and C. A. Rychert (2010), The Lithosphere-Asthenosphere Boundary, Annu. Rev. Earth Planet. Sci., 38(1), 551-575, doi:10.1146/annurev-earth040809-152438.

Gaillard, F., and G. I. Marziano (2005), Electrical conductivity of magma in the course of 
crystallization controlled by their residual liquid composition, J. Geophys. Res. Solid Earth, 110(B6), n/a-n/a, doi:10.1029/2004JB003282.

Gaillard, F., M. Malki, G. Iacono-Marziano, M. Pichavant, and B. Scaillet (2008), Carbonatite melts and electrical conductivity in the asthenosphere., Science, 322(5906), 1363-5, doi:10.1126/science.1164446.

Galer, S. J. G., and R. K. O’Nions (1986), Magmagenesis and the mapping of chemical and isotopic variations in the mantle, Chem. Geol., 56(1), 45-61, doi:http://dx.doi.org/10.1016/0009-2541(86)90109-9.

Gillet, P., P. Richet, F. Guyot, and G. Fiquet (1991), High-temperature thermodynamic properties of forsterite, J. Geophys. Res., B96, 11,805-11,816.

Goetze, C. (1977), A Brief summary of our present day understanding of the effect of volatiles and partial melt on the mechanical properties of the upper mantle, In High-Pressure Research, Applications in Geophysics edited by M. H. Manghnani and S-I Akimoto, pp. 323, Academic Press. NewYork

ten Grotenhuis, S. M., M. R. Drury, C. J. Spiers, and C. J. Peach (2005), Melt distribution in olivine rocks based on electrical conductivity measurements, J. Geophys. Res. Solid Earth, 110(12), 1-11, doi:10.1029/2004JB003462.

Hammond, W. C., and E. D. Humphreys (2000), Upper mantle seismic wave attenuation: Effects of realistic partial melt distribution, J. Geophys. Res., 105(B5), 10987-10999, doi:10.1029/2000jb900042.

Hansen RTJ, Bostock MG, Christensen NI (2012) Nature of the low velocity zone in Cascadia from receiver function waveform inversion. Earth Planet Sci Lett, 337-338:25-38. doi: 10.1016/j.epsl.2012.05.031 
Hier-Majumder, S. (2008), Influence of contiguity on seismic velocities of partially molten aggregates, J. Geophys. Res. Solid Earth, 113(12), 1-14, doi:10.1029/2008JB005662.

Hirano, N., E. Takahashi, J. Yamamoto, N. Abe, S. Ingle, I. Kaneoka, T. Hirata, J-I. Kimura, T. Ishii, Y. Ogawa, S. Machida, K. Suyehiro (2006), Volcanism in response to plate flexure., Science, 313(5792), 1426-1428, doi:10.1126/science.1128235.

Karato, S. (1990), The role of hydrogen in the electrical conductivity of the upper mantle, Nature, 347, 183-187, doi:10.1038/346183a0.

Karato S (1993) Importance of anelasticity in the interpritation of seismic tomography. Geophys Res Lett 20:1623-1626.

Karato, S. ichiro (2014), Does partial melting explain geophysical anomalies?, Phys. Earth Planet. Inter., 228, 300-306, doi:10.1016/j.pepi.2013.08.006.

Kawakatsu, H., P. Kumar, Y. Takei, M. Shinohara, T. Kanazawa, E. Araki, and K. Suyehiro (2009), Seismic Evidence for Sharp Boundaries of Oceanic Plates, Science, 24;324(5926):499-502

Kennett BLN, Engdahl ER, Buland R (1995) Constraints on seismic velocities in the Earth from traveltimes. Geophys J Int 122:108-124. doi: 10.1111/j.1365-246X.1995.tb03540.x

Kohlstedt, D. L. (1992), Structure, Rheology and Permeability of Partially Molten Rocks at Low Melt Fractions, in Mantle Flow and Melt Generation at Mid-Ocean Ridges, pp. 103-121, American Geophysical Union. Washington, DC.

Kono, Y., C. Park, T. Sakamaki, C. Kenny-Benson, G. Shen, and Y. Wang (2012), Simultaneous structure and elastic wave velocity measurement of $\mathrm{SiO} 2$ glass at high pressures and high temperatures in a Paris-Edinburgh cell., Rev. Sci. Instrum., 83(3), 33905, doi:10.1063/1.3698000. 
Jackson I, Gerald JDF, Faul UH, Tan BH (2002) Grain-size-sensitive seismic wave attenuation in polycrystalline olivine. J. Geophys. Res., 107:1-16. doi: 10.1029/2001JB001225

Jackson I, Faul UH, Fitz Gerald JD, Tan BH (2004) Shear wave attenuation and dispersion in melt-bearing olivine polycrystals: 1. Specimen fabrication and mechanical testing. J Geophys Res B Solid Earth 109:1-20. doi: 10.1029/2003JB002407

Laporte, D., and A. Provost (2000), The grain-scale distribution of silicate, carbonate and metallosulfide partial melts: a review of theory and experiments, in Physics and Chemistry of Partially Molten Rocks, edited by N. Bagdassarov, D. Laporte, and A. B. Thompson, pp. 93-140, Kluwer Academic, Norwell, Massachusetts.

Laporte, D., C. Rapaille, and A. Provost (1997), Wetting Angles, Equilibrium Melt Geometry, and the Permeability Threshold of Partially Molten Crustal Protoliths BT - Granite: From Segregation of Melt to Emplacement Fabrics, edited by J. L. Bouchez, D. H. W. Hutton, and W. E. Stephens, pp. 31-54, Springer Netherlands, Dordrecht.

Laske, G., A. Markee, J. A. Orcutt, C. J. Wolfe, J. A. Collins, S. C. Solomon, R. S. Detrick, D. Bercovici, and E. H. Hauri (2011), Asymmetric shallow mantle structure beneath the Hawaiian Swell-evidence from Rayleigh waves recorded by the PLUME network, Geophys. J. Int., 187(3), 1725-1742, doi:10.1111/j.1365-246X.2011.05238.x.

Laumonier, M., R. Farla, D. J. Frost, T. Katsura, K. Marquardt, A.-S. Bouvier, and L. P. Baumgartner (2017), Experimental determination of melt interconnectivity and electrical conductivity in the upper mantle, Earth Planet. Sci. Lett., 463(Supplement C), 286-297, doi:https://doi.org/10.1016/j.epsl.2017.01.037.

Li B, Liebermann RC (2007) Indoor seismology by probing the Earth’s interior by using sound velocity measurements at high pressures and temperatures. PNAS, 104:9145-9150. 
Li, L., M. Wentzcovitch, D. J. Weider and C. R. S. Da Silva (2007), Vibrational and thermodynamic properties of forsterite at mantle conditions, J. Geophys. Res., 112. doi:10.1029/2006JB004546.

Manthilake, M. A. G. M., T. Matsuzaki, T. Yoshino, S. Yamashita, E. Ito, and T. Katsura (2009), Electrical conductivity of wadsleyite as a function of temperature and water content, Phys. Earth Planet. Inter., 174(1-4), 10-18, doi:10.1016/j.pepi.2008.06.001.

Maumus, J. Bagdassarov, N. and H. Schmeling (2005), Electrical conductivity and partial melting of mafic rocks under pressure, Geochemica and Cosmochimica Acta, 69,47034178, doi:10.1016/j.gca.2005.05.010.

Mavko, G. . (1980), Velocity and attenuation in partially molten rocks, J. Geophys. Res., 85, 5173-5189.

Minarik, W. G., and E. B. Watson (1995), Interconnectivity of carbonate melt at low melt fraction, Earth Planet. Sci. Lett., 133(3-4), 423-437, doi:10.1016/0012-821X(95)00085-Q.

Naumov, V. B., V. A. Dorofeeva, A. V. Girnis, and V. V. Yarmolyuk (2014), Comparison of major, volatile, and trace element contents in the melts of mid-ocean ridges on the basis of data on inclusions in minerals and quenched glasses of rocks, Geochemistry Int., 52(5), 347-364, doi:10.1134/S0016702914050073.

Ni, H., H. Keppler, and H. Behrens (2011), Electrical conductivity of hydrous basaltic melts: Implications for partial melting in the upper mantle, Contrib. to Mineral. Petrol., 162(3), 637-650, doi:10.1007/s00410-011-0617-4.

Nielser, H. and I. Jackson (1989), Pressure derivatives of elastic wave velocities from ultrasonic interferometric measurements on jacketed polycrystals, J.Acoust. Soc. Am, 86, 1573-1585. Novella, D., D. J. Frost, E. H. Hauri, H. Bureau, C. Raepsaet, and M. Roberge (2014), The 
distribution of $\mathrm{H} 2 \mathrm{O}$ between silicate melt and nominally anhydrous peridotite and the onset of hydrous melting in the deep upper mantle, Earth Planet. Sci. Lett., 400, 1-13, doi:10.1016/j.epsl.2014.05.006.

O’Connell, R. J., and B. Budiansky (1974), Seismic velocities in dry and saturated cracked solids, J. Geophys. Res., 79(35), 5412-5426, doi:10.1029/JB079i035p05412.

Okumura, S., and N. Hirano (2013), Carbon dioxide emission to earth’s surface by deep-sea volcanism, Geology, 41(11), 1167-1170, doi:10.1130/G34620.1.

Pfeiffer, T. (1998), Viscosities and electrical conductivities of oxidic glass-forming melts, Solid State Ionics, 105(1), 277-287, doi:https://doi.org/10.1016/S0167-2738(97)00475-X.

Plank, T., and C. H. Langmuir (1992), Effects of the melting regime on the composition of the oceanic crust, J. Geophys. Res., 97(B13), 19749-19770, doi:10.1029/92jb01769.

Pommier, A., and E. J. Garnero (2014), Petrology-based modeling of mantle melt electrical conductivity and joint interpretation of electromagnetic and seismic results, J. Geophys. Res. Solid Earth, 119, 4001-4016, doi:10.1002/2014JB011567.

Pommier, A., K. Leinenweber, D. L. Kohlstedt, C. Qi, E. J. Garnero, S. J. Mackwell, and J. A. Tyburczy (2015), Experimental constraints on the electrical anisotropy of the lithosphereasthenosphere system, Nature, 522(7555), 202-206.

Presnall, D. C., C. L. Simmons, and H. Porath (1972), Changes in electrical conductivity of a synthetic basalt during melting, J. Geophys. Res., 77(29), 5665, doi:10.1029/JB077i029p05665.

Rivers ML, Carmichael ISE (1987) Ulstrasonic Studies of Silicate Melts. J Geophys Res, 92:9247-9270.

Roberts, J. J., and J. a. Tyburczy (1999), Partial-melt electrical conductivity: Influence of melt 
composition, J. Geophys. Res., 104(B4), 7055, doi:10.1029/1998JB900111.

Romanowicz, B. (1995), A global tomographic model of shear attenuation in the upper mantle, $J$. Geophys. Res., 100(B7), 12375, doi:10.1029/95JB00957.

Saal, A. E., E. H. Hauri, C. H. Langmuir, and M. R. Perfit (2002), Vapour undersaturation in primitive mid-ocean-ridge basalt and the volatile content of Earth’s upper mantle., Nature, 419(6906), 451-455, doi:10.1038/nature01073.

Sahagian, D. L., and A. A. Proussevitch (1998), 3D particle size distributions from 2D observations: stereology for natural applications, J. Volcanol. Geotherm. Res., 84(3), 173196, doi:https://doi.org/10.1016/S0377-0273(98)00043-2.

Salters, V. J. M., and S. R. Hart (1989), The hafnium paradox and the role of garnet in the source of mid-ocean-ridge basalts, Nature, 342, 420.

Sato, H., I. S. Sacks, T. Murase, G. Muncill, and H. Fukuyama (1989), Qp-melting temperature relation in peridotite at high pressure and temperature: Attenuation mechanism and implications for the mechanical properties of the upper mantle, J. Geophys. Res., 94(B8), 10647, doi:10.1029/JB094iB08p10647.

Schaeffer AJ, Bostock MG (2010) A low-velocity zone atop the transition zone in northwestern Canada. J Geophys Res, 115:B06302. doi: 10.1029/2009JB006856

Schmeling, H. (1986), Numerical models on the influence of partial melt on elastic, anelastic and electrical properties of rocks. Part II: electrical conductivity, Phys. Earth Planet. Inter., 43(2), 123-136, doi:10.1016/0031-9201(86)90080-4.

Schmerr, N. (2012), The Gutenberg discontinuity: melt at the lithosphere-asthenosphere boundary, Science, 335(6075), 1480-1483, doi:10.1126/science.1215433.

Shankland, T. J., and H. S. Waff (1977), Partial Melting and Electrical Conductivity Anomalies 
in the Upper Mantle, J. Geophys. Res., 82(33), 5409-5417.

Shea, T., B. F. Houghton, L. Gurioli, K. V Cashman, J. E. Hammer, and B. J. Hobden (2010), Textural studies of vesicles in volcanic rocks : An integrated methodology, J. Volcanol. Geotherm. Res., 190(3-4), 271-289, doi:10.1016/j.jvolgeores.2009.12.003.

Sifré, D., E. Gardés, M. Massuyeau, L. Hashim, S. Hier-Majumder, and F. Gaillard (2014), Electrical conductivity during incipient melting in the oceanic low-velocity zone., Nature, 509(7498), 81-5, doi:10.1038/nature13245.

Soustelle, V., and G. Manthilake (2017), Deformation of olivine-orthopyroxene aggregates at high pressure and temperature: Implications for the seismic properties of the asthenosphere, Tectonophysics, 694, 385-399, doi:10.1016/j.tecto.2016.11.020.

Stixrude, L., and C. Lithgow-Bertelloni (2005), Mineralogy and elasticity of the oceanic upper mantle: Origin of the low-velocity zone, J. Geophys. Res. B Solid Earth, 110(3), 1-16, doi:10.1029/2004JB002965.

Takei, Y. (1998), Constitutive mechanicarl elationso f solid-liquidc omposites in terms of grainboundary contiguit, J. Geophys. Res., 103(B8), 18183-18203.

Takei, Y. (2000), Acoustic properties of partially molten media studied on a simple binary system with a controllable dihedral angle, J. Geophys. Res., 105(B7), 16665, doi:10.1029/2000JB900124.

Takei, Y. (2002), Effect of pore geometry on V P / V S : From equilibrium geometry to crack, $J$. Geophys. Res., 107(B2), 2043, doi:10.1029/2001JB000522.

Toomey, D. R., W. S. D. Wilcock, S. C. Solomon, W. C. Hammond, and J. A. Orcutt (1998), Mantle Seismic Structure Beneath the MELT Region of the East Pacific Rise from P and S Wave Tomography Mantle Seismic Structure Beneath the MELT Region of the East Pacific 
Rise from P and S Wave Tomography the primary ocean bottom seismometer, Science (80-. )., 280(May), 1224-1227, doi:10.1126/science.280.5367.1224.

Toomey, D. R., D. Jousselin, R. a Dunn, W. S. D. Wilcock, and R. S. Detrick (2007), Skew of mantle upwelling beneath the East Pacific Rise governs segmentation., Nature, 446(7134), 409-414, doi:10.1038/nature05679.

Tyburczy, J. A., and H. S. Waff (1983), Electrical conductivity of molten basalt and andesite to 25 kilobars pressure: Geophysical significance and implications for charge transport and melt structure, J. Geophys. Res., 88(2), 2413-2430, doi:10.1029/JB088iB03p02413.

von Bargen, N., and H. S. Waff (1986), Permeabilities, interfacvial areas and curvatures of partially molten systems: results of numerical computations of equilibrium microstructures, J. Geophys. Res., 91, 9261-9276.

Waff, H. S. (1974), Theoretical consideration of electrical conductivity in a partially molten mantle and implications for geothermometry, J. Geophys. Res., 79(26), 4003-4010.

Waff, H. S., and J. R. Blau (1982), Experimental determination of near equilibrium textures in partially molten silicates at high pressures, in High Pressure Research in Geophysics, edited by S. Akimoto and M. H. Manghnani, pp. 229-236, Center for Academic Publication, Tokyo.

Waff, H. S., and U. H. Faul (1992), Effects of crystalline anisotropy on fluid distribution in ultramafic partial melts, J. Geophys. Res., 97(B6), 9003, doi:10.1029/92JB00066.

Wagner, L., D. W. Forsyth, M. J. Fouch, and D. E. James (2010), Detailed three-dimensional shear wave velocity structure of the northwestern United States from Rayleigh wave tomography, Earth Planet. Sci. Lett., 299(3-4), 273-284, doi:10.1016/j.epsl.2010.09.005.

Widmer, R., G. Masters, and F. Gilbert (1991), Spherically symmetric attenuation within the 

246X.1991.tb05700.x.

914

Yoshino, T., Y. Takei, D. A. Wark, and E. B. Watson (2005), Grain boundary wetness of texturally equilibrated rocks, with implications for seismic properties of the upper mantle, $J$. Geophys. Res. B Solid Earth, 110(8), 1-16, doi:10.1029/2004JB003544.

Yoshino, T., Y. Nishihara, and S. ichiro Karato (2007), Complete wetting of olivine grain boundaries by a hydrous melt near the mantle transition zone, Earth Planet. Sci. Lett., 256(3-4), 466-472, doi:10.1016/j.epsl.2007.02.002.

Yoshino, T., D. Yamazaki, and K. Mibe (2009), Well-wetted olivine grain boundaries in partially molten peridotite in the asthenosphere, Earth Planet. Sci. Lett., 283(1-4), 167-173, doi:10.1016/j.epsl.2009.04.007.

Yoshino, T., M. Laumonier, E. McIsaac, and T. Katsura (2010), Electrical conductivity of basaltic and carbonatite melt-bearing peridotites at high pressures: Implications for melt distribution and melt fraction in the upper mantle, Earth Planet. Sci. Lett., 295(3-4), 593-602, doi:10.1016/j.epsl.2010.04.050.

Zhang, B., T. Yoshino, D. Yamazaki, G. Manthilake, and T. Katsura (2014), Electrical conductivity anisotropy in partially molten peridotite under shear deformation, Earth Planet. Sci. Lett., 405, 98-109, doi:10.1016/j.epsl.2014.08.018. 


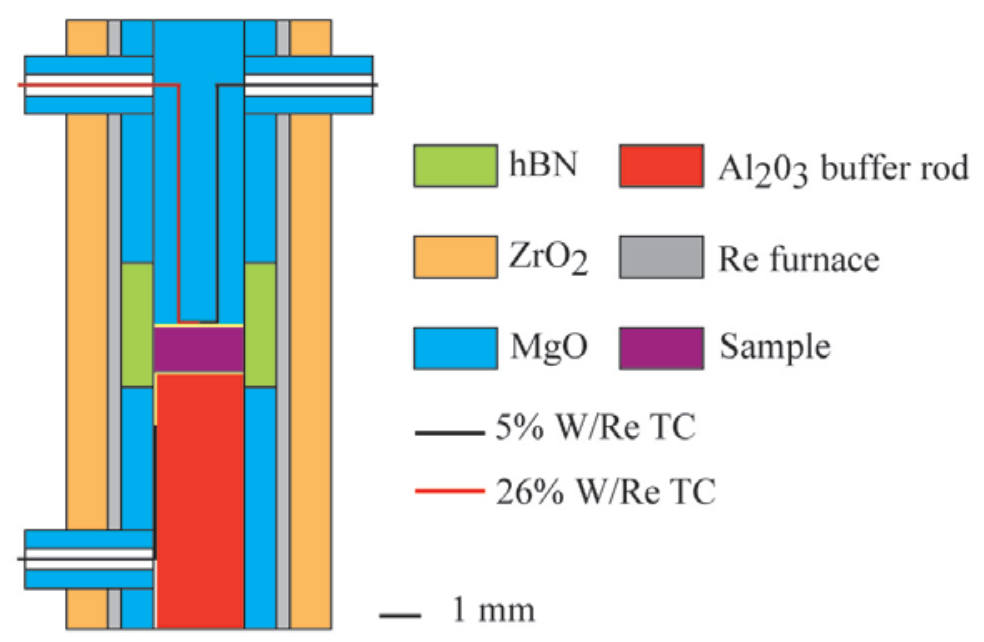

933 Figure 1. Schematic cross section of the high pressure cell assembly for simultaneous acoustic 934 velocity and electrical conductivity measurements. The assembly was designed in order to place 935 the sample at the centre of the cell at high pressure due to differential compression of alumina 936 and MgO pistons. The respective pistons lengths were calibrated in prior experiments. 

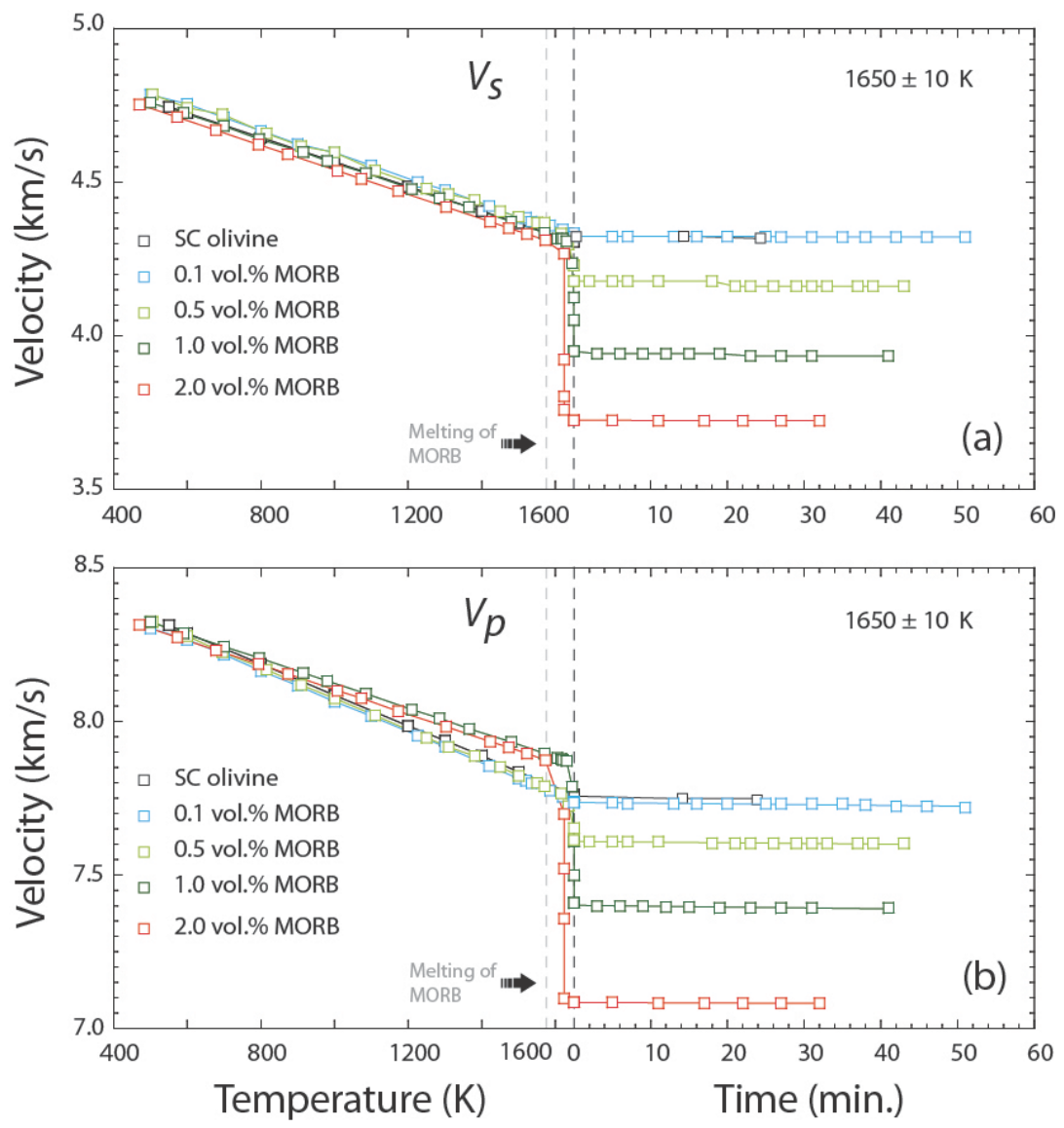

938 Figure 2. (a) $S$ - and (b) $P$ - wave velocities as a function of increasing temperature (left) and as a 939 function of time at a constant temperature (right) for olivine- and melt-bearing samples 940 investigated in this study. The uncertainty results from the estimations of temperature, pressure, 941 sample dimensions and data fitting errors and are estimated to be lower $2.6 \%(2 \sigma)$ of the value. 942 Errors are not represented for visibility. Temperature error $(10 \mathrm{~K}(2 \sigma))$ is within the symbol for 943 all data points. 


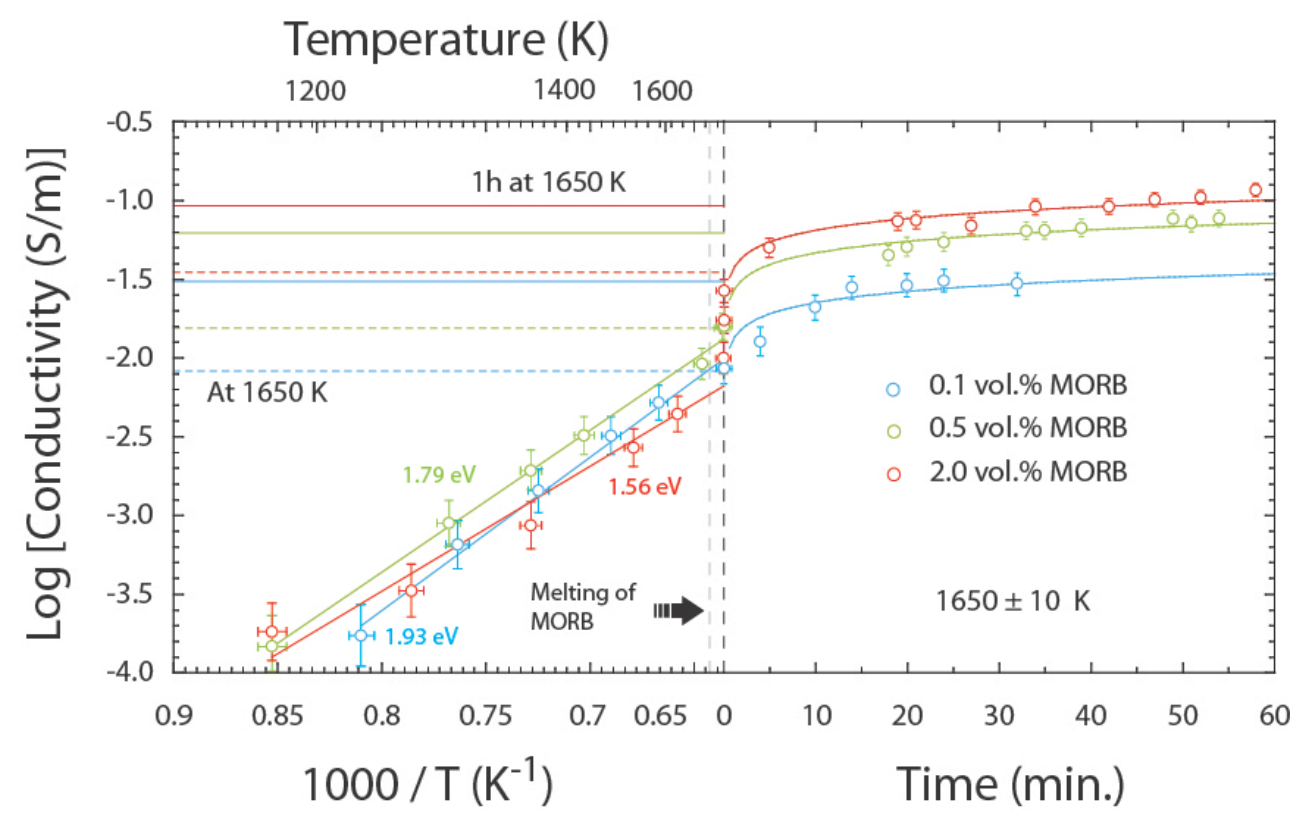

945 Figure 3. Electrical conductivity as a function of reciprocal temperature (left) and, as a function 946 of time at a constant temperature (right), for the samples containing $0.1,0.5$ and 2 vol. \% melt 947 fractions. Solid and dashed lines indicate the corresponding conductivities immediately after 948 melting and after 1 hour at constant temperature of $1650 \mathrm{~K}$. The uncertainties associated with the 949 electrical conductivity data measurements are less at high temperatures. The uncertainty results 950 from the estimations of temperature, pressure, sample dimensions and data fitting errors and are 951 less than for EC $5 \%(2 \sigma)$ of the value. Error in temperature is $10 \mathrm{~K}(2 \sigma)$. 

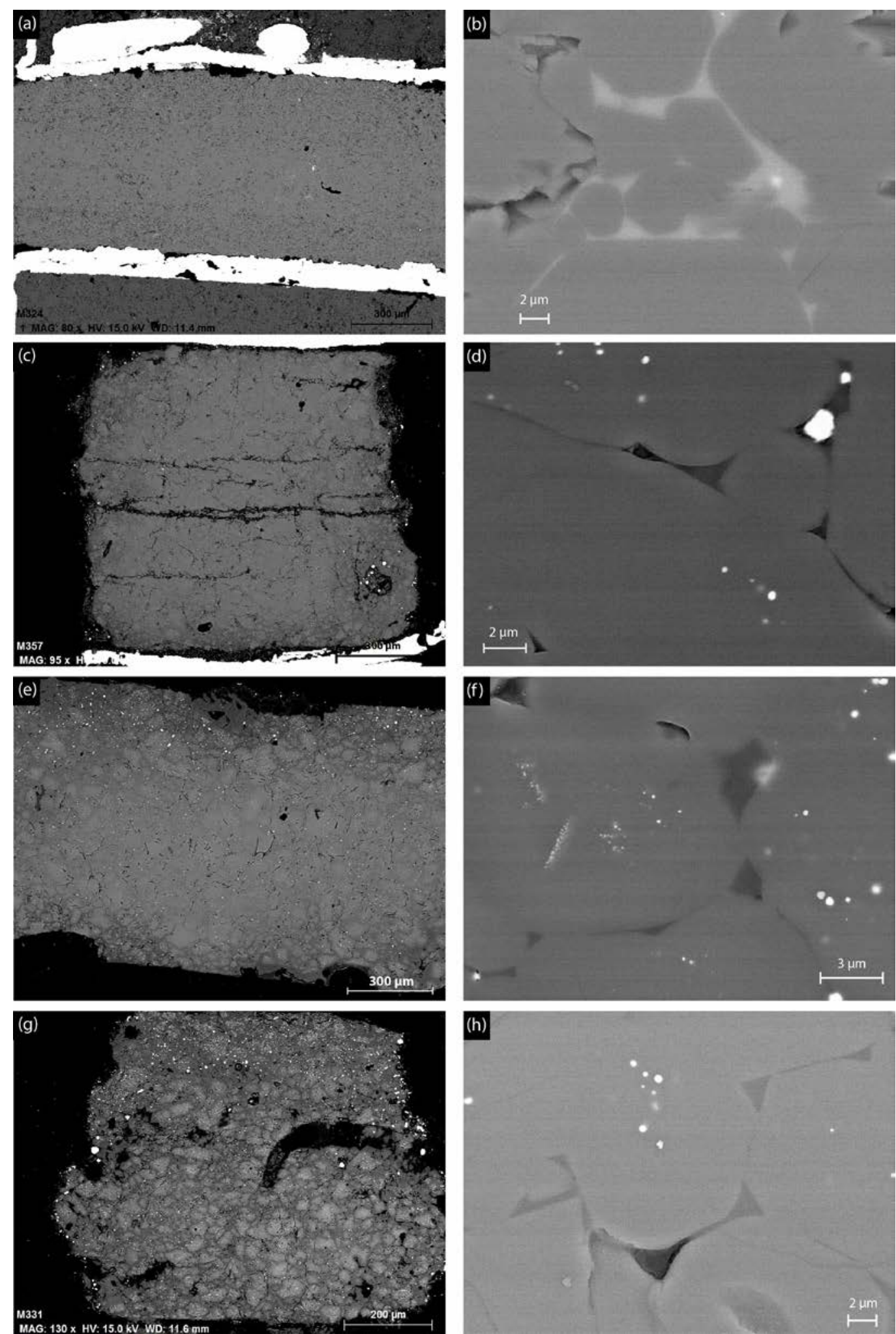

953 Figure 4. Backscattered electron (BSE) images showing equilibrium melt textures at meltolivine interfaces at $1650 \mathrm{~K}$. Well-developed interconnected melt channels in samples with (a, b) 
955

956

957

958

959

960

961

962

$2.0 \%$, (c, d) $1.0 \%$, (e, f) $0.5 \%$ and $(\mathbf{g}, \mathbf{h}) 0.1 \%$ melt volume fractions. The bright particles attached on sample surface and holes are rhenium pellets coming from polishing (TC's, furnace and electrodes are made of Re). Biggest particles are presents in samples holes and along sample/capsule interface (4c and 4g) whereas smallest particles are attached to sample surface along polishing scratches (well visible in 4f).
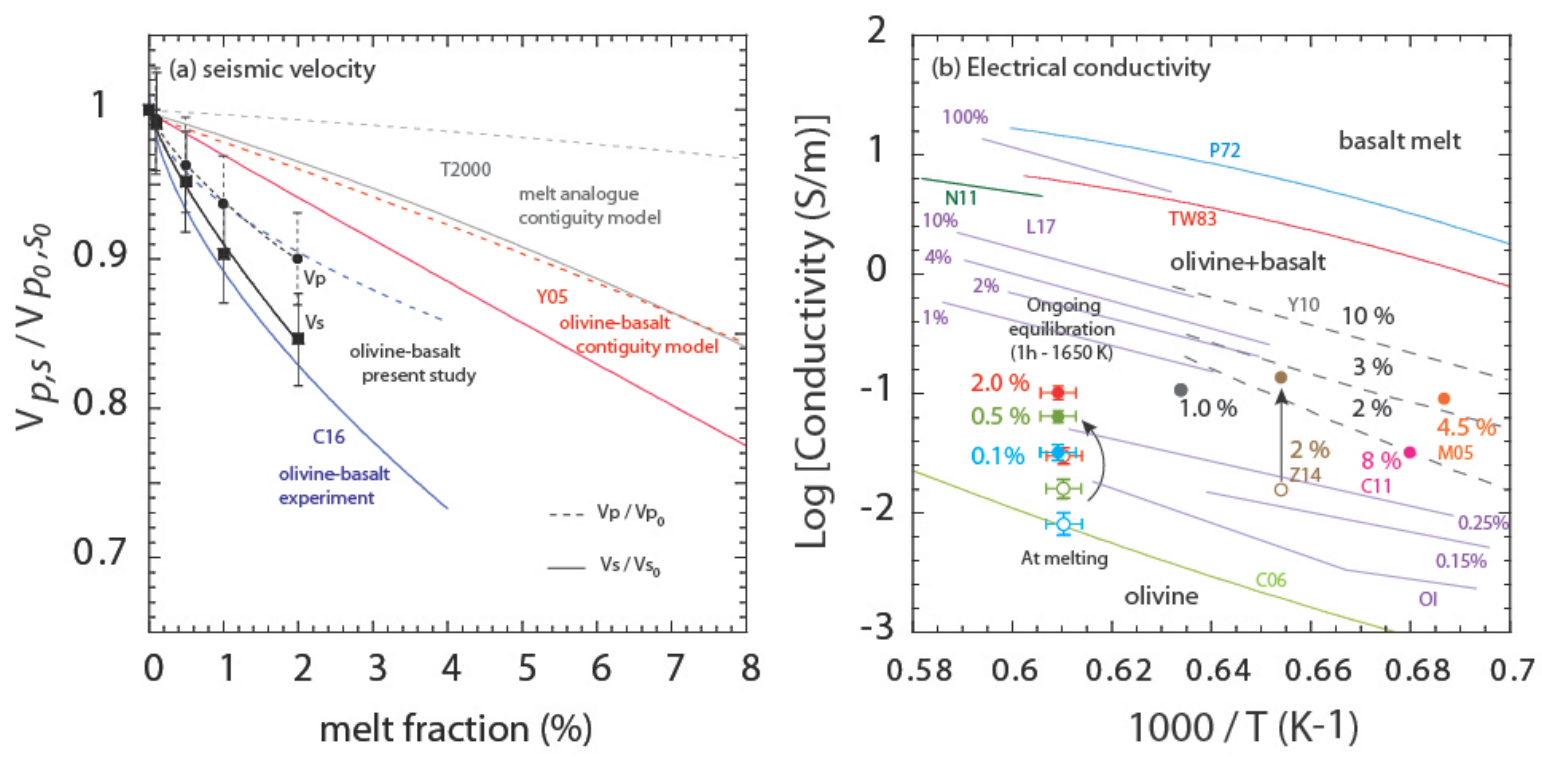

Figure 5. Comparison of reported acoustic velocities and electrical conductivities for partially molten systems. (a) $\mathrm{Vp}, \mathrm{s} / \mathrm{Vp}_{0}, \mathrm{~s}_{0}$ ratios for various melt fractions. Experimentally determined velocities for the olivine-basalt system [Chantel et al., 2016] and theoretical estimations for olivinebasalt [Yoshino et al., 2005] and melt analogue systems [Takei, 2000] are shown for comparison. Errors in SV ratio are $3.6 \%(2 \sigma)$, errors in melt fraction are within the data symbol (1\% relative). (b) Reported electrical conductivity values for olivine, MORB and olivine + MORB compositions. Open circles and filled circles indicate our conductivity data for our volatile-bearing partial melts at melting and data after $1 \mathrm{~h}$ a $1650 \mathrm{~K}$. The conductivity values presented in the figure are C06 [Constable, 2006], P72 [Presnall et al., 1972], TW83 [Tyburczy and Waff, 1983], N11 [Ni et al., 2011], Y10 [Yoshino et al., 2010], Z14 [Zhang et al., 2014], C11 [Caricchi et al., 2011], M05 
971 [Maumus et al., 2005] and L17 [Laumonier et al., 2017]. The EC values reported in [Zhang et al., 972 2014] indicate melt conductivity before (open circle) and after (solid circle) the textural 973 modifications due to the shear deformation. Errors on our data points are $5 \%(2 \sigma)$ on EC value and $97410 \mathrm{~K}(2 \sigma)$ in temperature.

975

976

977

978

979

980

981

982 983

984 985 986

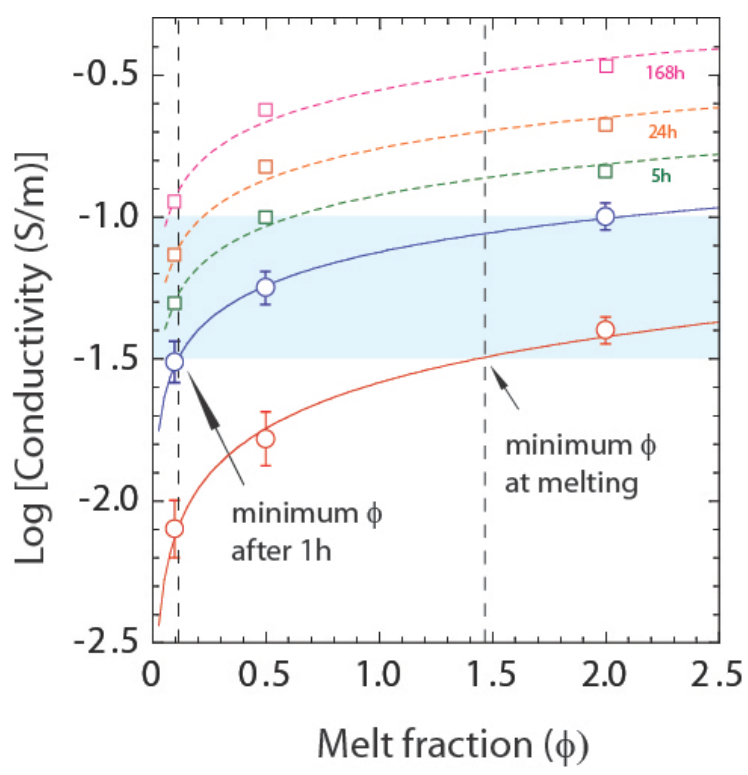

Figure 6. The comparisons of electrical conductivity before and after $1 \mathrm{~h}$ at $1650 \mathrm{~K}$ for studied melt fractions. The conductivity corresponding to the LVZ is shown by the blue shaded area. The vertical lines indicate the minimum melt fractions required to explain the high conductivity zone in the asthenosphere. Extrapolated data using the logarithmic laws fitted from data in figure 3 were represented from relevant time-scales with squares. This slow increase shows that weeks of equilibration will be necessary to have half an order of magnitude increase of EC. Such an increase is compatible with measurements performed on equilibrated material after weeks of annealing. Errors on EC are $5 \%(2 \sigma)$ and within the data symbol for melt fraction (1 \% relative). Errors on extrapolated values are $10 \%(2 \sigma)$ and we not displayed for distinction with measured data points. 

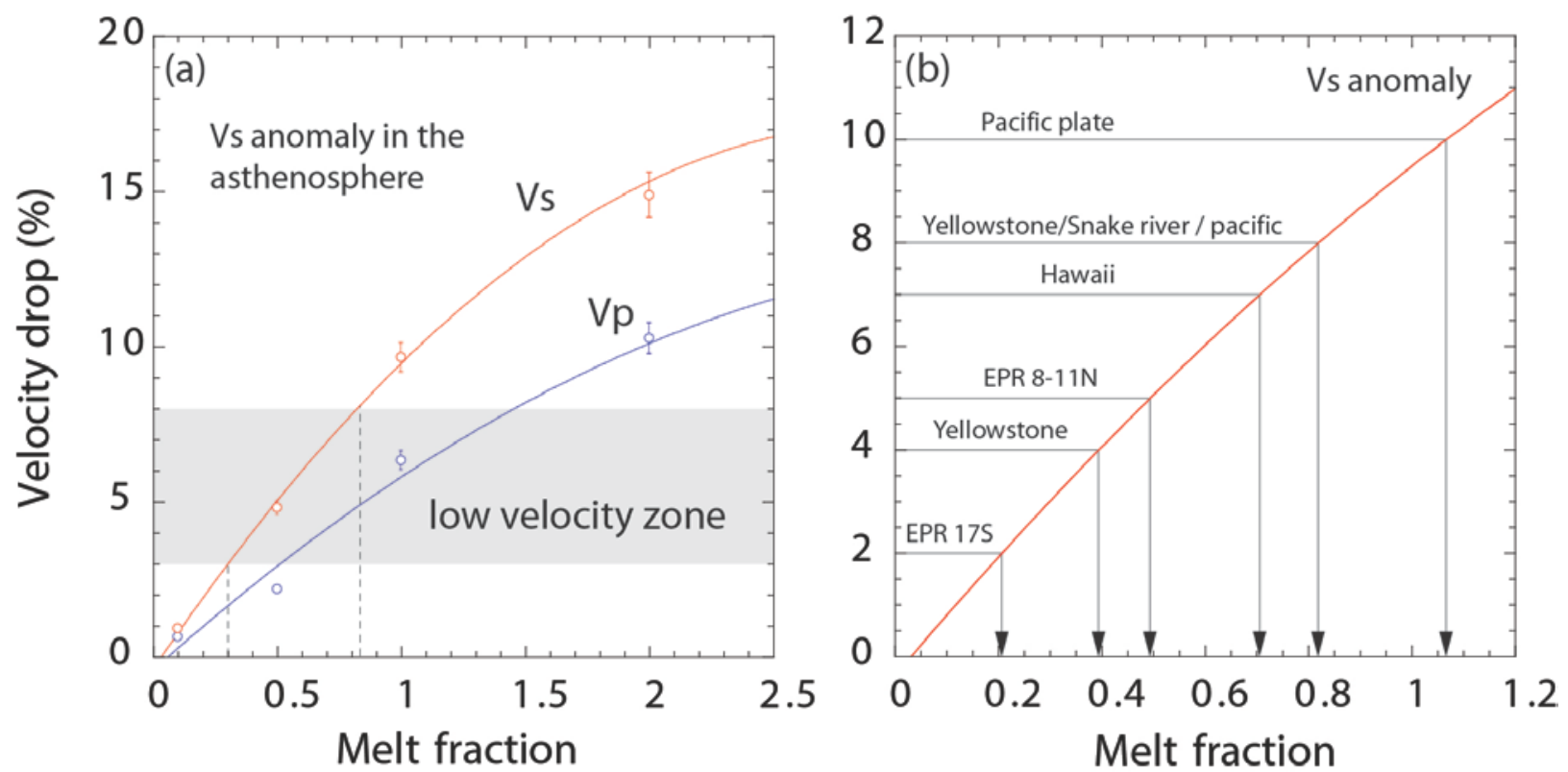

988 Figure 7. (a) The \% drop in P- and S-wave velocity as a function of the sample melt fraction.

989

990

991

992

993

994

995

996

The geophysically observed S- wave velocity anomaly for the LVZ in the asthenosphere is shown by the shaded rectangle. Note that the 3-8 \% Vs drop observed for most of the asthenosphere can be explained by $0.3-0.8 \%$ melt. (b) Vs velocity anomalies observed at various geological settings and the possible melt fraction estimations based on our model. The Vs anomalies presented in the figure are from EPR 17S [Toomey et al., 1998], EPR 8-11N [Toomey et al., 2007], Yellowstone-Snake River [Wagner et al., 2010], Hawaii [Laske et al., 2011], and the Pacific [Kawakatsu et al., 2009; Schmerr, 2012]. Errors on velocity drops are $5 \%$ (2б) relative and within the symbol for melt fraction (1 \% relative). 

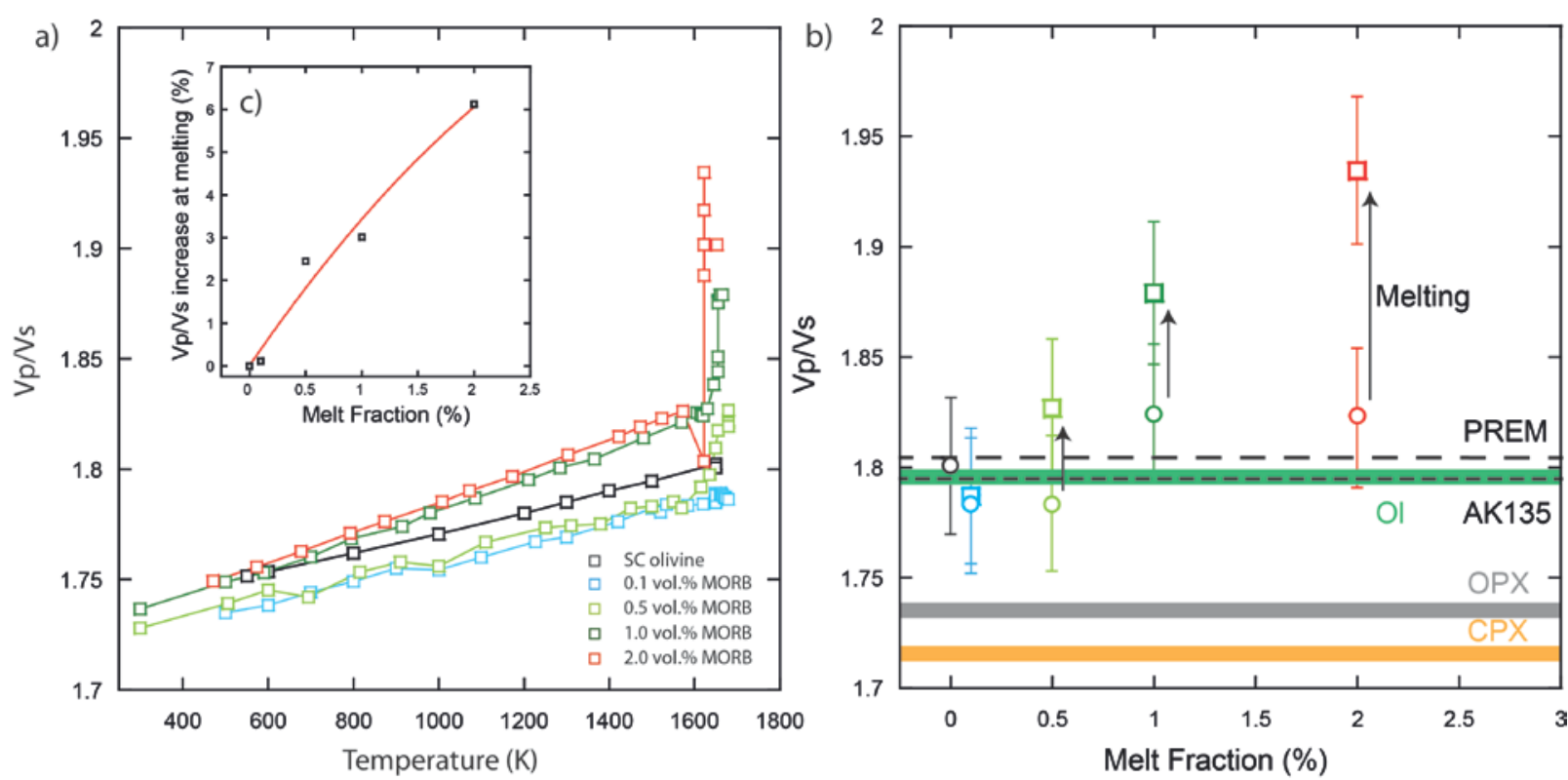

997

998

999

1000

1001

1002

1003

1004

1005

1006

1007

1008

1009

1010

Figure 8. (a) Vp/Vs ratio of our experiments reported as a function of increasing temperature.

The standard deviation on the data lies between 0.305 and 0.335 (lowest to highest temperature values) corresponding to an error majored by $1.75 \%$ of the $\mathrm{Vp} / \mathrm{Vs}$ ratio $(1 \sigma) . \mathrm{b}) \mathrm{Vp} / \mathrm{Vs}$ ratio as a function of the volume melt fraction (MORB content). Values for solid sample before melting are represented by circles and values after partial melting occurred with squares. Vp/Vs ratios from seismological data: PREM [Dziewonski and Anderson, 1981] and AK135 [Kennett et al., 1995] are represented in black dashed lines. Vp/Vs ratios from nominal minerals are represented by colored zones (green for Olivine, grey for OPX and gold for CPX), velocities data at 2.5 GPa were taken from [Li and Liebermann, 2007]. c) Inset figure in a) Vp/Vs ratio increase at melting in function of melt fraction, quantifying the magnitude of increase of the ratio in response to partial melting. 


\begin{tabular}{lcccc}
\hline & $\begin{array}{c}\text { MORB } \\
\text { initial }\end{array}$ & $\begin{array}{c}\text { MORB } \\
\text { final }\end{array}$ & $\begin{array}{c}\text { Olivine } \\
\text { initial }\end{array}$ & $\begin{array}{c}\text { Olivine } \\
\text { final }\end{array}$ \\
\hline $\mathbf{S i O}_{2}$ & $50.73(0.28)$ & $51.15(0.1)$ & $41.97(0.8)$ & $41.43(0.4)$ \\
$\mathbf{T i O}_{2}$ & $2.00(0.02)$ & $2.22(0.27)$ & $0.06(0.02)$ & $0.03(0.02)$ \\
$\mathbf{A l}_{2} \mathbf{O}_{3}$ & $13.73(0.18)$ & $14.54(0.1)$ & $0.1(0.03)$ & $0.1(0.01)$ \\
$\mathbf{F e O}$ & $11.29(0.13)$ & $9.20(0.1)$ & $9.3(0.3)$ & $9.15(0.2)$ \\
$\mathbf{M n O}$ & $0.2(0.2)$ & $0.22(0.1$ & $0.11(0.03)$ & $0.12(0.04)$ \\
$\mathbf{M g O}$ & $7.1(0.12)$ & $6.94(0.09)$ & $48.65(0.9)$ & $49.69(0.7)$ \\
$\mathbf{C a O}$ & $10.94(0.22)$ & $11.41(0.03)$ & $0.23(0.1)$ & $0.22(0.01)$ \\
$\mathbf{N a} \mathbf{O} \mathbf{O}$ & $2.83(0.07)$ & $2.26(0.3)$ & $<0.01$ & $<0.01$ \\
$\mathbf{K} \mathbf{O}$ & $0.15(0.08)$ & $0.35(0.1)$ & $<0.01$ & $<0.01$ \\
\hline $\mathbf{T o t a l}$ & $\mathbf{9 8 . 7 9 ( 0 . 5 )}$ & $\mathbf{9 8 . 2 9 ( 0 . 2 )}$ & $\mathbf{1 0 0 . 4 ( 0 . 2 )}$ & $\mathbf{1 0 0 . 7 ( 0 . 8 )}$ \\
\hline
\end{tabular}

1013

1014

Table 1. Chemical composition of MORB and olivine before and after the experiments. 